\title{
RELACIONES ENTRE TORTUGAS MARINAS Y SERES HUMANOS EN LA COSTA DE ATACAMA: DOS EJEMPLOS ARQUEOLÓGICOS
}

\author{
RELATIONS BETWEEN HUMANS AND SEA TURTLES IN THE COAST OF \\ ATACAMA: TWO ARCHAEOLOGICAL EXAMPLES
}

Benjamín Ballestera, Rafael labarcab \& Elisa Calas ${ }^{c}$

La arqueología del litoral del desierto de Atacama ha concentrado sus estudios en un espectro reducido de animales, sobrerrepresentando los más tradicionales, conocidos y populares, como peces, camélidos y otáridos, en desmedro de otros con un registro más acotado pero igualmente significativo. Presentamos una reflexión acerca de las relaciones entre seres humanos y tortugas marinas, destacando la diversidad de estrategias, instancias y mecanismos a través de los cuales estas relaciones se construían y actuaban.

Palabras clave: Chelonioidea, Caza marina, Relaciones interespecie, costa del norte de Chile.

The archaeology from the Atacama Desert littoral had centered their studies into a reduced animal spectrum, over representing those more traditional, known, and popular, as fishes, camelids and otarides, in detriment of others, with a less bounded but equally significant register. We present a reflection about humans and sea turtles relationships, practically absents from the bestiary of the northern Chile littoral populations, focusing in their interespecies relations, highlighting the diversity of strategies, instances, and mechanism through which this those relations where constructed and acted.

Keywords: Chelonioidea, marine hunting, interspecies relationship, northern chilean coast.
El litoral del desierto de Atacama es uno de los ecosistemas marinos más ricos y productivos de todo el mundo, debido a la corriente de Humboldt y al sistema de surgencia costera que alimentan la franja litoral con aguas frías ricas en nitrógeno y fósforo desde mar adentro (Daneri et al. 2000, Thiel et al. 2007). Producto de lo anterior, el océano Pacífico alberga una enorme biodiversidad de especies marinas dentro de una compleja cadena trófica, que incluye desde distintos microorganismos animales y vegetales hasta algunos de los más grandes cetáceos y peces del mar (Camus \& Andrade 1999, Palma \& Apablaza 2004, Medina et al. 2004, entre otros).

En este espacio geográfico, poblaciones humanas han cazado, pescado y recolectado en el mar, la costa y el desierto de manera prácticamente ininterrumpida al menos desde los 11000 cal. AP (Lindberg 1967, Llagostera 1979, Castelleti 2007, Contreras 2010, Escobar 2015, Salazar et al. 2015, Ballester 2017, entre otros). Antes de la llegada de los europeos a la región, los colectivos humanos asentados en el litoral establecieron, en su formación como sociedad, un estrecho vínculo con los

\footnotetext{
A Benjamín Ballester, umR7041 ArScAN, Équipe Ethnologie Préhistorique, Université Paris 1 Panthéon-Sorbonne, París, E-mail: benjaminballesterr@gmail.com

B Rafael Labarca, Instituto de Ciencias Ambientales y Evolutivas y Transdisciplinary Center for Quaternary Research in the South of Chile, Universidad Austral de Chile, Valdivia, E-mail: r.labarca.e@gmail.com

c Elisa Calas, Sociedad Chilena de Arqueología, Santiago, E-mail: elisa.calas@gmail.com
} 
animales marinos, no solo por ser la principal fuente alimenticia y de materias primas, sino también porque fueron seleccionados como referentes simbólicos y de sentido en su construcción cultural, imaginario social y cosmología (Mostny \& Niemeyer 1983, Niemeyer 1985, Contreras et al. 2008, Ballester \& Gallardo 2016, Ballester 2018).

Lamentablemente, el valor que estas especies marinas pudieron tener para estas sociedades no ha sido completamente reconstruido por la arqueología (Bittmann 1986, Valenzuela et al. 2015), ya que muchos de los animales que habitan el área de estudio aún no han sido identificados en el registro arqueológico. Un ejemplo de ello son los quelonioídeos que, siendo los reptiles más importantes del ambiente litoral, se encuentran completamente invisibilizados en la prehistoria local (Yáñez 1951, Frazier \& Salas 1982, Azócar et al. 2011).

En el presente artículo buscamos revalorar la relación entre tortugas marinas y seres humanos en el litoral del desierto de Atacama a través de dos ejemplos arqueológicos particulares. El primero, a partir del análisis de los restos esqueletales y de caparazón de tortugas presentes en el conchal-basural de Playa Miller (PML-5), ubicado inmediatamente al sur de la ciudad de Arica (Bird 1943). El segundo corresponde al estudio de las representaciones de escenas de caza de tortugas marinas con embarcaciones y arpones en el arte rupestre de El Médano, emplazadas en la quebrada homónima en la localidad de Paposo, al norte de Taltal (Mostny \& Niemeyer 1983, 1984, Niemeyer 2010) (fig. 1). En ambos casos se utilizó la premisa común de la anatomía comparada, ya que por un lado identificamos taxonómicamente los restos óseos de tortugas al confrontarlos a esqueletos de especímenes conocidos, y por otro, determinamos los motivos representados en el arte rupestre en función de los rasgos morfológicos y anatómicos característicos de cada especie. El estudio de la diversidad de contextos y soportes arqueológicos, que incluyen basuras domésticas, adornos corporales, expresiones de arte rupestre y sitios funerarios, nos permitió realizar una primera aproximación acerca de la relación entre las tortugas marinas y los seres humanos del norte de Chile en distintos campos de lo social, como la subsistencia, el conocimiento del medio, el simbolismo, los aspectos cognitivos y sus referentes culturales.

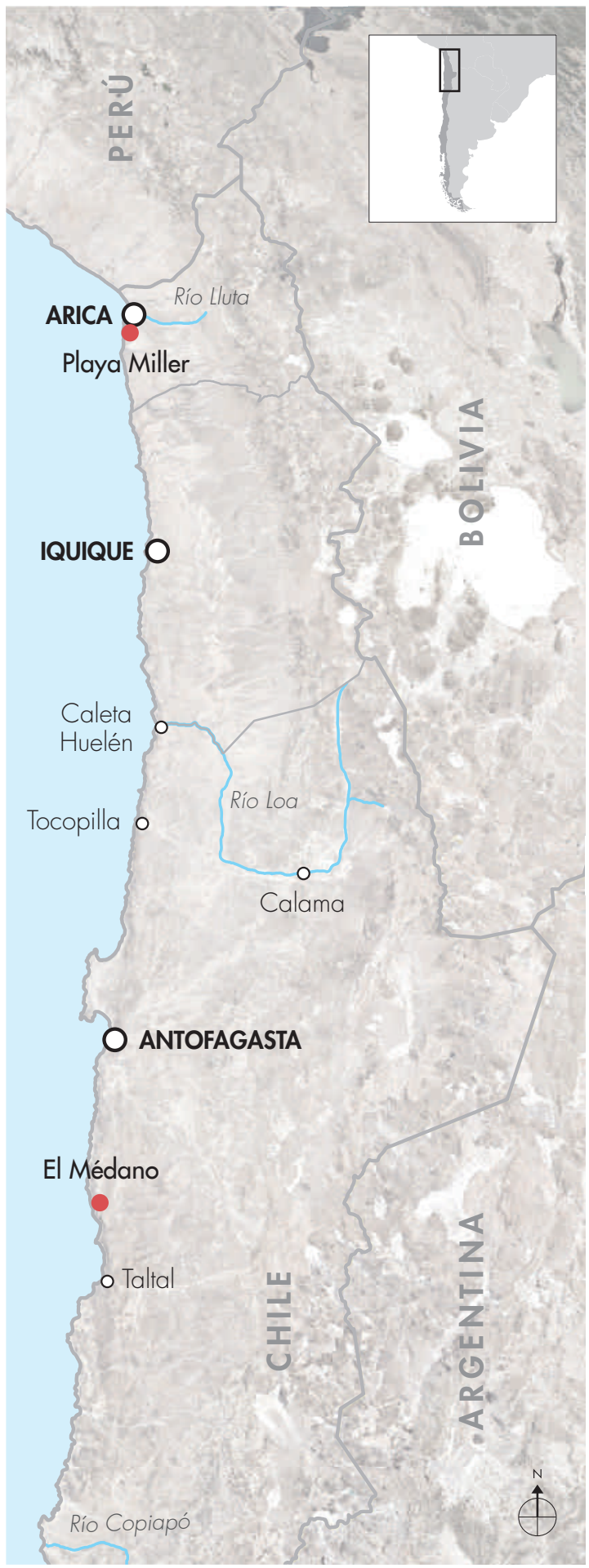

Figura 1. Mapa del norte de Chile con la ubicación de los principales sitios arqueológicos con restos y pinturas de tortugas marinas. Figure 2. Map of northern Chile showing the location of the main archeological sites with sea turtle remains and paintings. 


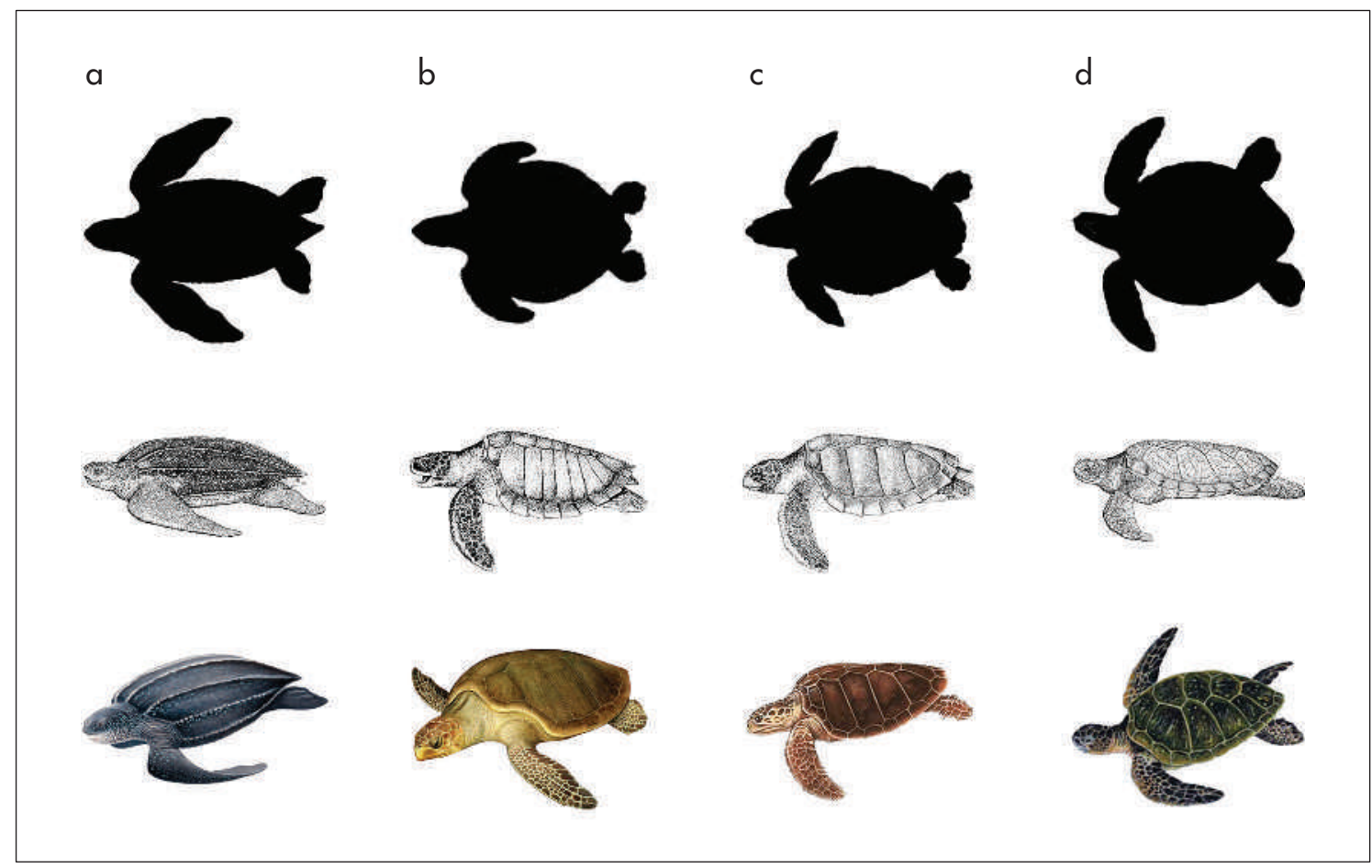

Figura 2. Especies de tortugas marinas presentes en la costa norte de Chile: a) Dermochelys coriacea; b) Lepidochelys olivacea; c) Caretta caretta; d) Chelonia mydas. Hilera de imágenes superiores tomadas de Pritchard \& Mortimer (2000: figura 3). Figure 2. Species of sea turtles present on the coast of northern Chile: a) Dermochelys coriácea; b) Lepidochelys olivácea; $c$ ) Caretta caretta; d) Chelonia mydas. The row of images at top were taken from Pritchard \& Mortimer (2000: figure 3).

\section{ECOLOGÍA, TAXONOMÍA Y DISTRIBUCIÓN DE TORTUGAS MARINAS EN LA COSTA NORTE DE CHILE}

Las tortugas son los reptiles más importantes de los mares chilenos y han habitado las costas del océano Pacífico al menos desde el Cretácico (Canales \& Álvarez 2015, Sarmiento-Devia et al. 2015). Actualmente, su distribución geográfica va desde la frontera norte con el Perú hasta los fiordos australes, con registros de avistamientos a lo largo de casi todo el litoral nacional (Philippi 1899, Yáñez 1951, Frazier \& Salas 1982, Frazier 1990, Ibarra-Vidal \& Ortiz 1990, Azócar et al. 2011).

Cuatro de las siete especies reconocidas a nivel mundial han sido registradas en Chile: Dermochelys coriacea Valdelli 1761 (Quelonioídea: Dermochelyidae), Lepidochelys olivacea Eschscholtz 1829 (Quelonioídea: Cheloniidae), Caretta caretta Rafinesque 1814 (Quelonioídea: Cheloniidae) y Chelonia mydas Linnaeus 1758 (Quelonioídea: Cheloniidae), conocidas popularmente como laúd o coriácea, olivácea (Ridley en inglés y pico de loro en Perú), boba y verde, respectivamente (Frazier \& Salas 1982, Frazier 1990, Azócar et al. 2011, SarmientoDevia et al. 2015) (fig. 2).

Para ninguna de las cuatro especies se han documentado anidaciones en el territorio chileno, por lo que su avistamiento se debe a sus circuitos migratorios desde zonas de reproducción, siguiendo cardúmenes para su alimentación (Donoso-Barros 1965, Frazier \& Salas 1982). Por esto, el mayor número de registros ocurre en época estival, salvo Ch. mydas, que aparece esporádicamente en invierno (Frazier 1990). Debido al mismo fenómeno, predominan los individuos maduros (Frazier 1990). De acuerdo con Azócar y colaboradores (2011), los registros de tortugas marinas desde 1884 hasta la fecha prueban que su presencia en costas chilenas no es producto de eventos de tipo oceanográfico-atmosférico ENOS (El Niño/Oscilación del Sur), ni tampoco de la desorientación de sus circuitos habituales de movilidad, sino más bien de sus rutas migratorias regulares para las cuales esta región litoral es parte integral, pues constituye un área de alimentación. 


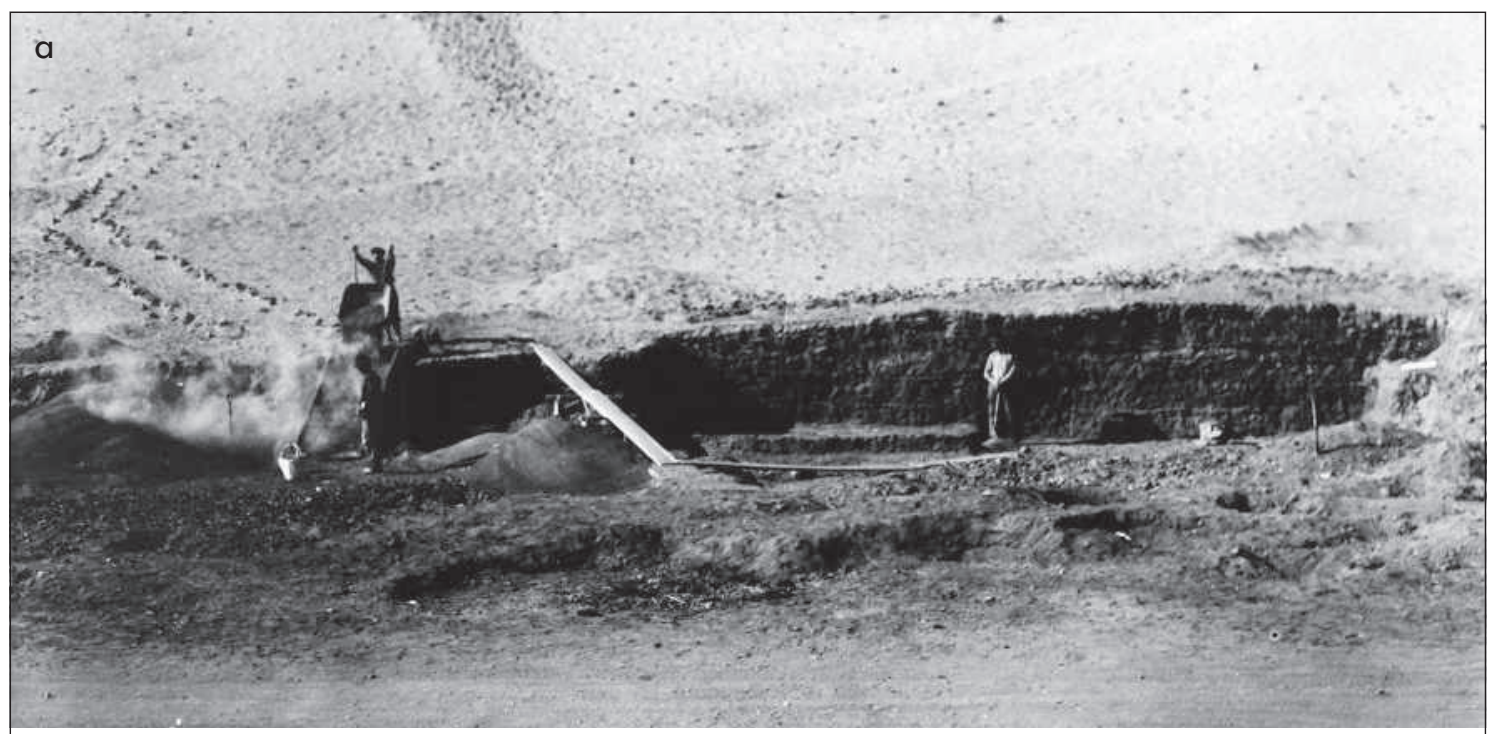

b

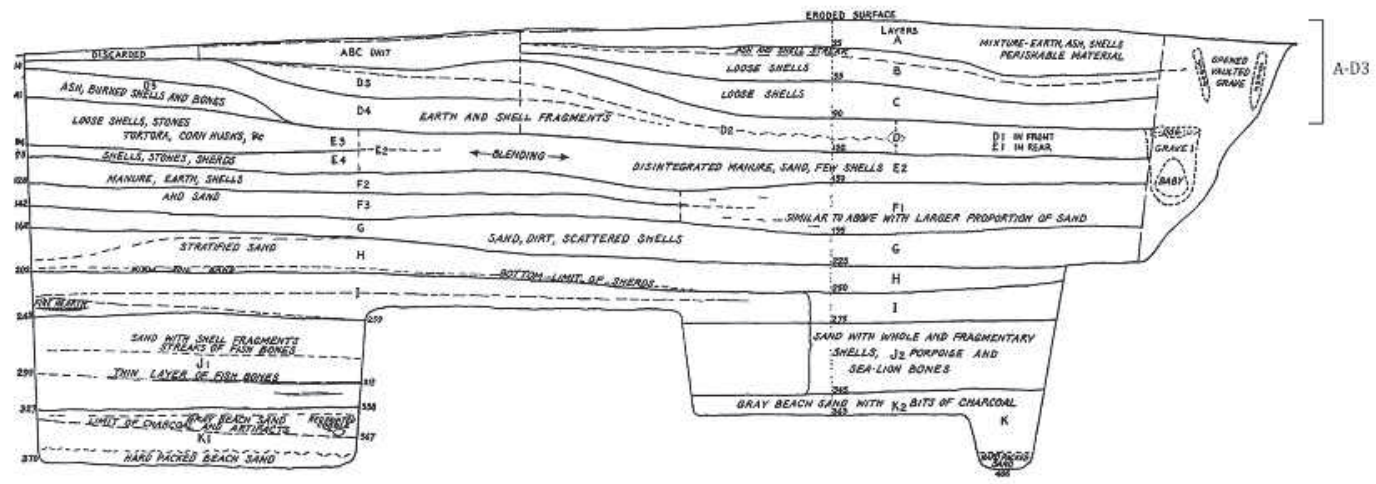

Figura 3. Excavaciones de Junius Bird en el sitio de PML-5: a) fotografía del momento de las excavaciones (cortesía del AMNH); b) perfil estratigráfico de la secuencia del sitio (Bird 1943: 193, figura 5). Figure 3. Excavations by Junius Bird at the PML-5 site: a) photo of the excavations in progress (courtesy of AMNH); b) Stratigraphic profile of the site sequence (Bird 1943: 193, figure 5).

\section{CASOS DE ESTUDIO ARQUEOLÓGICOS}

\section{Restos de tortugas marinas en el conchal-basural de Playa Miller, Arica}

El conchal doméstico de Playa Miller 5 (PML-5) $\left(18^{\circ} 20^{\prime} 32^{\prime \prime} \mathrm{S} / 70^{\circ} 19^{\prime} 30^{\prime \prime O}\right)$ se emplaza sobre la segunda terraza litoral en una pequeña bahía protegida de 150 metros de largo, al sur de la ciudad de Arica (fig. 1). La excavación de una trinchera realizada por Junius Bird (1943) dejó al descubierto once capas estratigráficas en una secuencia depositacional de cuatro metros de potencia (fig. 3: a). De acuerdo con el material cultural recuperado, los 2,5 metros superiores (capas A-H) corresponderían a una ocupación durante los períodos Intermedio Tardío, Tardío e Histórico del sector (posterior al 1000 cal. AP), mientras que las capas inferiores ( $\mathrm{I}-\mathrm{K})$ pertenecerían a momentos previos al uso de la tecnología cerámica (anterior a los $3500 \mathrm{cal}$. AP) (fig. 3: b). El sitio no cuenta con dataciones radiocarbónicas y su cronología solo se ha podido trazar a través del material cultural diagnóstico, como la cerámica, los artefactos formatizados y ciertos vegetales cultivados.

El material arqueológico recuperado del componente superior está integrado por diversos artefactos relacionados con la recolección, pesca y caza marina, junto a fragmentos de cerámica, esteras, cordelería en 
fibra animal y vegetal, desechos e instrumentos líticos, entre otros. En el conjunto de basuras domésticas destacan restos óseos de peces, mamíferos marinos y aves, además de valvas de moluscos, maíces, calabazas y porotos. Junius Bird (1943: 211) indicó brevemente la presencia de restos de caparazón de tortugas provenientes de las ocupaciones portadoras de cerámica (componente superior), así como en las capas tempranas del vecino conchal-basural de Quiani 1, ubicado cerca de dos kilómetros al sur de Playa Miller (Bird 1943: 237), sin discutir la asignación taxonómica en ambos casos.

\section{Representaciones de tortugas marinas en el arte rupestre de El Médano, Taltal}

El Médano corresponde a una de las numerosas quebradas que descienden desde la cordillera de la costa hacia la planicie litoral en la Región de Antofagasta $\left(24^{\circ} 49^{\prime} 00^{\prime \prime} \mathrm{S} / 70^{\circ} 30^{\prime} 08^{\prime \prime} \mathrm{O}\right)$ (fig. 1). A lo largo de la quebrada, entre los 600 y $1300 \mathrm{msnm}$, se han registrado cientos de pinturas rupestres que dieron origen al estilo homónimo. Se trata de representaciones esencialmente naturalistas y figurativas, cuyos motivos más comunes son los animales marinos, las embarcaciones y las escenas de caza, estas últimas definidas por trazos lineales que representan las sogas de los arpones (Mostny \& Niemeyer 1983, 1984, Núñez \& Contreras 2008, Berenguer 2009, Niemeyer 2010, Gallardo et al. 2012, Ballester \& Gallardo 2016, Ballester 2018, entre otros) (fig. 4). Los animales fueron pintados siguiendo cánones estéticos y representacionales bastante similares, reproduciendo los principales rasgos fisionómicos de cada una de las especies marinas, especialmente su forma general y los elementos anatómicos. Entre los taxones identificados se reconocen ballenas, delfines, tiburones, albacoras, lobos marinos, jibias y tortugas. Fuera del ámbito netamente marino, destacan camélidos y algunas figuras antropomorfas (Mostny \& Niemeyer 1983, 1984, Núñez \& Contreras 2008, Niemeyer 2010, Ballester 2018, Ballester et al. 2018). En el universo rupestre del estilo El Médano priman las escenas de caza marina por sobre otras labores de subsistencia, como la pesca y la recolección, así como también de aquellas artesanales, artísticas, el cuidado de niños, la cocina, la construcción, entre otras realizadas por estos colectivos litorales para su reproducción social. Esta distinción visual buscó probablemente posicionar diferencialmente esta práctica y a sus agentes en el ámbito de las representaciones, cumpliendo sin lugar a dudas un rol ideológico en
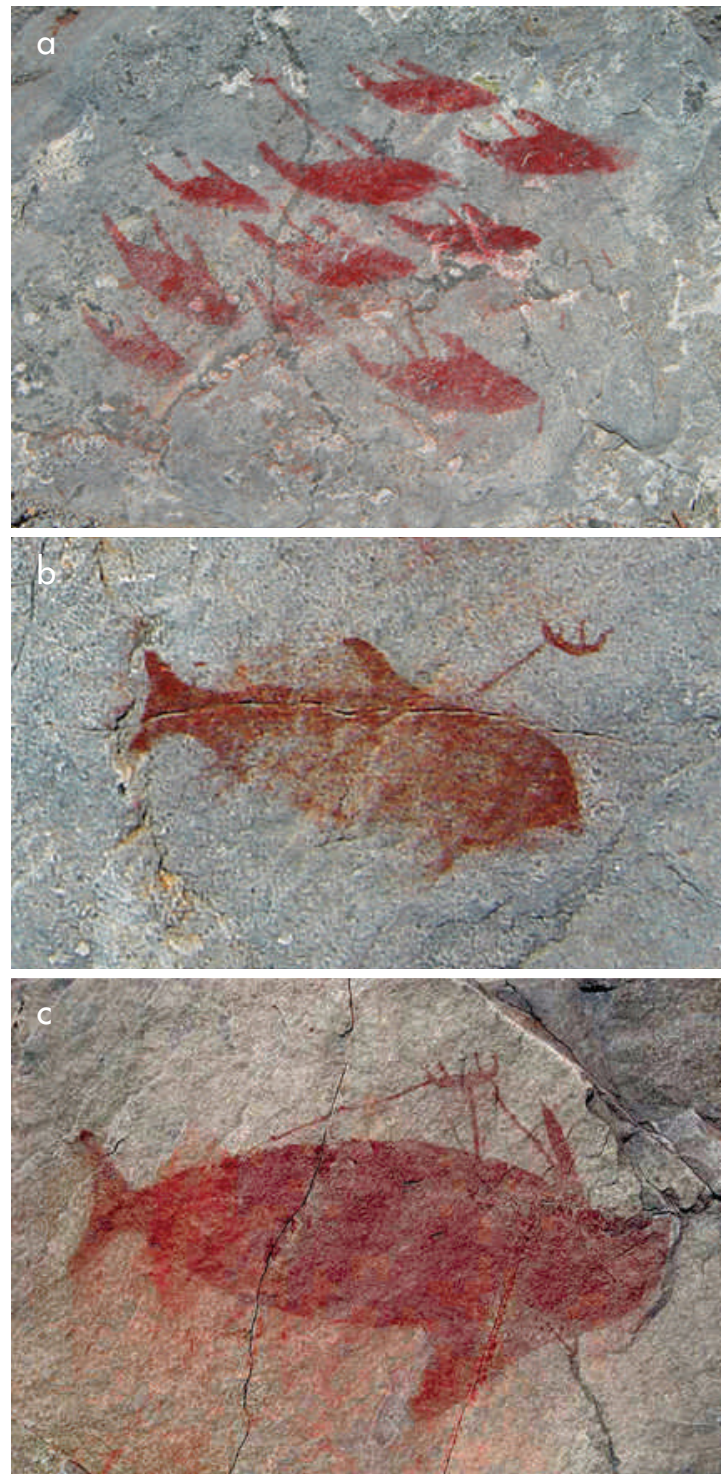

Figura 4. Algunos de los motivos característicos del arte rupestre de El Médano (fotografías: Francisco Gallardo). Figure 4. Some characteristic motifs found in the rock art of El Médano (photos by: Francisco Gallardo).

la sociedad (Mostny \& Niemeyer 1983, 1984, Berenguer 2009, Ballester \& Gallardo 2016; Ballester 2018).

Nuevos sitios con pinturas rupestres de este estilo han sido descubiertos, ampliando su distribución geográfica y la magnitud de la instalación artística (Núñez \& Contreras 2008, Ballester \& Gallardo 2016, Monroy et al. 2016, Ballester 2018). Si bien su distribución espacial se concentra aproximadamente en $100 \mathrm{~km}$ de costa entre Botija $\left(24^{\circ} 30^{\prime} 18^{\prime \prime} \mathrm{S}\right)$ y Taltal $\left(25^{\circ} 23^{\prime} 06^{\prime \prime} \mathrm{S}\right)$, 
recientes descubrimientos a más de $250 \mathrm{~km}$ al norte han expandido sus límites geográficos (Ballester et al. 2015).

La definición cronológica de este estilo es compleja. Recientemente se publicó un fechado Ams de una pintura emplazada en un alero litoral que arrojó un resultado de $7882 \pm 160$ AP (Castelleti et al. 2015, Goguitchaichvili et al. 2016); sin embargo, los depósitos estratigráficos del mismo sitio demostraron que el inicio de la ocupación no sería anterior a los 1200 cal. AP (Ballester 2016). Existe igualmente una discordancia temporal entre esta datación absoluta y los elementos iconográficos representados en los motivos de El Médano (p. ej. balseros con tocados cefálicos de cronología tardía y escenas de caza de camélidos con arcos y flechas), así como también con la prehistoria del litoral desértico y las formas de composición de este estilo rupestre respecto de otros de la región (Mostny \& Niemeyer 1983, 1984, Berenguer 2009, Niemeyer 2010, Gallardo et al. 2012, Ballester 2016, 2018). Por otro lado, se han señalado falencias en la metodología de muestreo junto con la no consideración de posibles factores de contaminación del panel datado (Ballester 2016, 2018). En este contexto, parece más seguro sugerir que el arte rupestre de El Médano presenta expresiones que se restringen al menos desde los 2000 cal. AP hasta antes de la llegada del mundo europeo a la región (Ballester 2016, 2018).

\section{MATERIALES Y MÉTODOS}

La revisión de los materiales óseos de PML-5, ubicados en el American Museum of Natural History de Nueva York, permitió reconocer cuatro especímenes: una mandíbula y tres fragmentos del caparazón, provenientes de distintos estratos del sitio, desde la capa A hasta la D3 (tabla 1; fig. 3b), correspondientes a las capas superiores y más tardías del depósito basural (Bird 1943).

Para la identificación anatómica y determinación taxonómica se consultaron todos los esqueletos de referencia existentes en la sección de Zoología del Museo Nacional de Historia Natural de Santiago de Chile: $L$. olivacea (MNHN 1512, 1589, 1972 y s/N), y Chelonia sp. (MNHN 1588 y 1970), los que fueron complementados con trabajos osteológicos y de identificación generales (Márquez 1990, Wyneken 2001, 2003, Jones et al. 2012, Sheil 2013). Para evaluar eventuales afinidades métricas entre los especímenes arqueológicos y de referencia, se tomaron cuatro medidas básicas de la mandíbula (fig.
5): (1) largo máximo mandibular, medido desde el punto más anterior del hueso dentario al más posterior del hueso articular; (2) largo máximo de la superficie masticatoria del dentario, medido desde el punto más anterior al más posterior de la superficie masticatoria del dentario; (3) ancho máximo mandibular, medido entre los puntos más mediales de ambos surangulares; y (4) alto máximo mandibular, medido a partir de una línea recta desde la base del dentario hasta el punto más dorsal del coronoides. La pieza arqueológica fue comparada métricamente además con todos los especímenes actuales de L. olivacea, C. caretta, E. imbricata y Ch. mydas del Repositorio de Cráneos de Tortugas Marinas del Centro Interdisciplinario de Ciencias Marinas del Instituto Politécnico Nacional (APRCTM-CICIMAR-IPN), La Paz, México. La descripción y nomenclatura de los especímenes se basa en Gaffney (1979) y Zangerl (1969).

En el caso de los especímenes de caparazón se evaluó, en la medida de lo posible, su posición y lateralidad en función de la presencia de ciertos rasgos anatómicos, como las articulaciones con las costillas y vértebras en su faz interior, además de la dirección, morfología y asociación de surcos en su parte exterior, con el objeto de inferir la posición de placas vertebrales y costales.

Respecto del arte rupestre de El Médano, las actividades se concentraron en: (1) determinar el tipo de escenas en las que se encontraban insertos los testudines, (2) reconocer las estrategias de captura de estos animales e (3) intentar identificar taxonómicamente las especies representadas. Para lo primero se emplearon los elementos iconográficos que acompañaban a las tortugas en las composiciones de las escenas rupestres, siguiendo las definiciones de motivos utilizados anteriormente para este estilo (Mostny \& Niemeyer 1983, 1984, Berenguer 2009, Niemeyer 2010, Gallardo et al. 2012, Ballester 2018). Para lo segundo se consideraron elementos tecnológicos que hacen referencia a la captura de dichos animales en las representaciones, como el número de embarcaciones, tripulantes y líneas de caza, así como la cantidad y puntos de anclaje de los arpones sobre cada animal (Ballester 2018). Finalmente, para la clasificación taxonómica se analizaron elementos fisionómicos característicos de los animales, como las proporciones de las unidades anatómicas, formas de los caparazones, tamaño relativo, disposición de las patas y prominencias de colas y cabezas, siguiendo las descripciones morfológicas y fisionómicas disponibles en la literatura (Donoso-Barros 1965, Frazier \& Salas 
Tabla 1. Restos arqueológicos de tortugas del sitio Playa Miller 5 (PML-5). Table 1. Archaeological turtle remains at the Playa Miller 5 site (PML-5).

\begin{tabular}{|c|c|c|c|c|c|c|c|c|c|c|}
\hline \multicolumn{2}{|c|}{ CONTEXTO } & \multirow{2}{*}{$\frac{\text { MUSEO }}{\text { No INVENTARIO }^{\circ}}$} & \multirow[t]{2}{*}{ OBJETO } & \multirow{2}{*}{$\begin{array}{c}\text { STATUS DE } \\
\text { MANUFACTURA }\end{array}$} & \multirow{2}{*}{\begin{tabular}{c|} 
SECCIÓN \\
ANATÓMICA
\end{tabular}} & \multicolumn{4}{|c|}{ MEDIDAS (mm/g) } & \multirow{2}{*}{$\begin{array}{c}\text { FIGURA } \\
6\end{array}$} \\
\hline SITIO & CAPA & & & & & LARGO & ANCHO & ESPESOR & PESO & \\
\hline P. Miller & A & $41.1 / 4302$ & Pendiente & Terminado & Caparazón & 42 & 35 & 7,1 & 6,1 & $\mathrm{H}$ \\
\hline P. Miller & B & $41.1 / 5200 \mathrm{~A}$ & Placa & Fragmento & Caparazón & 99,6 & 56,5 & 6 & 30,8 & A-D \\
\hline P. Miller & $\mathrm{C}$ & $41.1 / 5201$ & Mandíbula & & Cabeza & & & & & E-F \\
\hline P. Miller & D3 & $41.1 / 4703$ & Pendiente & Terminado & Caparazón & 48,6 & 39 & 4 & 8,7 & G \\
\hline
\end{tabular}

1982, Pritchard \& Mortimer 2000, Azócar et al. 2011, Sarmiento-Devia et al. 2015). La información morfológica y anatómica de cada especie se detalla a continuación:

D. coriacea (fig. 2a) se caracteriza por un caparazón alargado tipo barril y acintado hacia la parte posterior. Es el único espécimen de las costas chilenas que no tiene placas o escudos exteriores. La silueta de su cuerpo podría definirse como ovalada y alargada. Sus extremidades anteriores son considerablemente largas a diferencia de las posteriores, cuyo tamaño es mucho más reducido. Posee una cabeza pequeña, un cuello restringido, y una cola ancha y prolongada.

L. olivacea (fig. 2b) corresponde a la menor de las variedades de tortugas. Su caparazón es ancho y redondeado, aunque ligeramente puntiagudo hacia la sección posterior. Sus aletas delanteras no son tan pronunciadas, pero aun así son más largas que las traseras, estas últimas ubicadas muy cercanas una a la otra. Su cabeza es alargada y su cola poco notoria.

En C. caretta (fig. 2c) destaca un caparazón ancho y redondeado en su segmento posterior, de silueta oval, más largo que ancho. Sus aletas delanteras son cortas y las traseras, si bien son de talla reducida, se encuentran levemente distancias entre sí. Su cola es angosta y sobresale del borde del caparazón. La cabeza es gruesa en el cuello y un poco puntiaguda.

El caparazón de Ch. mydas (fig. 2d) es de forma circular a oval, casi tan ancho como largo, aunque con su sección posterior relativamente aguzada. Las extremidades delanteras son comparativamente largas y las traseras están

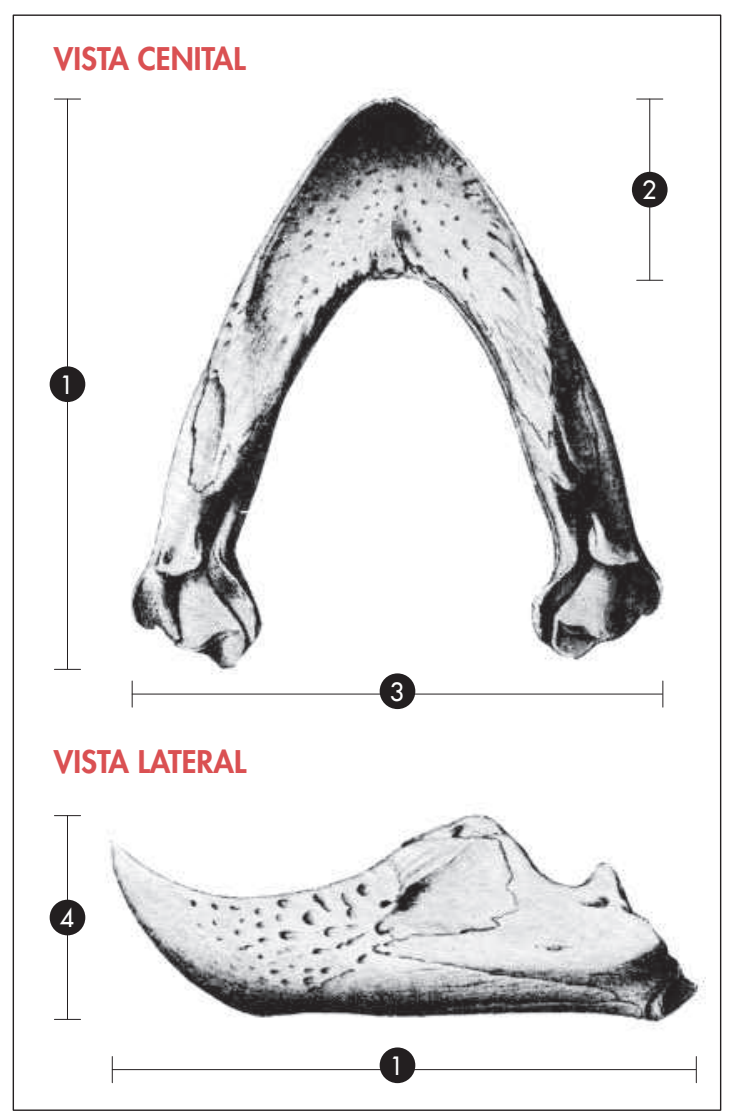

Figura 5. Variables métricas para el hueso mandibular utilizadas en el presente estudio: 1) largo máximo mandibular; 2) largo máximo de la superficie masticatoria del dentario; 3 ) ancho máximo mandibular; 4) alto máximo mandibular (dibujo corresponde a Lepidochelys kempii, en Gaffney 1979: figura 211). Figure 5. Metric variables for the mandibular bone used in this study: 1) maximum mandibular length; 2) maximum length of the dental chewing surface; 3) maximum mandibular width; 4) maximum mandibular height (the drawing corresponds to Lepidochelys kempi, in Graffney 1979: figure 211. 
notoriamente separadas entre sí. La cabeza es alargada y sobresaliente, de forma redondeada y con un cuello angosto. Su cola es poco prominente.

\section{RESULTADOS}

\section{Los restos óseos}

Dos de los fragmentos óseos del caparazón se encuentran intensamente modificados para la confección de colgantes o pendientes (fig. 6 e-f), tal como lo sugiere la perforación ubicada en uno de los extremos de ambas piezas y en el cordel amarrado en uno de ellos (fig. 6f). Este último posee una forma subrectangular, trabajado por abrasión, completamente pulido en sus vértices, aristas y caras principales, adelgazando notablemente su espesor. El segundo posee una forma pentagonal, de bordes irregulares y caras no pulidas (fig. 6e). Las piezas han perdido su morfología original por lo que no pueden ser asociadas a ninguna unidad ósea del caparazón en particular. De esta manera, solo se asignan a nivel de Familia (Cheloniidae indet.), descartando a D. coriacea.

Un tercer ejemplar corresponde a un hueso pleural derecho fracturado en su tercio lateral (fig. 6 a-d). Posee sección levemente cóncava y forma subrectangular, aunque con una pequeña curvatura hacia caudal, lo que sugiere que podría ubicarse en el segmento caudal del caparazón. Por su cara ventral (fig. 6c), hacia medial, es posible advertir el inicio de la cabeza de la costilla, mientras que en su cara dorsal se aprecian tres surcos a modo de "Y" (fig. 6 a-b), los que indican la disposición de las placas vertebrales y costales exteriores. La baja diagnosis del material solo permite su asignación a nivel de Familia (Cheloniidae indet.), descartando a D. coriacea.

El cuarto espécimen es una mandíbula prácticamente completa (fig. 7) dominada por el hueso dentario ubicado en su porción anterior, en el cual el área en que se emplaza la ranfoteca es plana, bien proyectada anteroposteriormente y en vista dorsal posee una morfología en "U". El primero de estos atributos permite descartar que se trate de $D$. coriacea, debido a que esta posee un escaso desarrollo de la porción anterior del dentario. El segundo rasgo no es compatible con E. imbricata, cuyo segmento anterior del dentario posee una morfología en "V". Ambas características, en cambio, son compartidas por las especies del género Lepidochelys (L. olivacea y L. kempii), C. caretta y Ch. mydas. En el espécimen arqueológico (fig. 7), el dentario se encuentra en contacto hacia el lado posterior con el hueso surangular. La parte posterior de este desciende hacia ventral desde el hueso coronoides de manera abrupta, para volver a proyectarse hacia dorsal en un proceso bien definido que se encuentra parcialmente fracturado. Este rasgo es propio del género Lepidochelys, ya que en Ch. mydas y en C. caretta, el surangular desciende de manera comparativamente más suave, generando una proyección muy poco desarrollada hacia dorsal. Considerando la ausencia de L. kempii en el área de estudio -restringida a aguas del Atlántico nororiental- (Márquez 1990), la mandíbula arqueológica pudo ser asignada a L. olivacea. Métricamente, las medidas de la pieza arqueológica se agrupan tanto con esta última especie como con $C$. caretta, ambas conformando un grupo "grande". Sin embargo, el largo de la superficie masticatoria del dentario (medida 2) separa, en términos métricos, a ambas especies (tabla 2; fig. 8).

\section{Las representaciones rupestres}

En el sitio de El Médano, cuatro paneles ubicados en dos sectores de la quebrada (MD-002 y MD-018) exhiben representaciones de tortugas marinas (tabla 3; fig. 9). Todos los quelonioídeos se encuentran ligados a escenas de caza mediante el uso de embarcaciones y líneas de arpón. Los cuatro son motivos compuestos donde la escena se compone de una sola embarcación en forma de media luna con un tripulante montado, asociado a una única tortuga (relación 1:1:1 entre las unidades de la composición; una balsa, un tripulante y una tortuga). El animal se encuentra en las cuatro imágenes dispuesto en una perspectiva de planta (dorsal o ventral), con un cuerpo abultado que representa la forma de su caparazón, radiado por cuatro patas o aletas, dos delanteras y dos traseras, siempre destacando una cabeza prominente y redondeada, además de la presencia, en dos de las pinturas, de colas entre las extremidades traseras (fig. 9 b-c). En tres de los motivos las tortugas están representadas horizontalmente y en paralelo al eje de la embarcación (fig. 9 b-c-d), mientras que solo en una la presa se orientó verticalmente y perpendicular al eje de la balsa (fig. 9a). En los cuatro motivos el animal fue dibujado de un tamaño mayor a la embarcación y su tripulante, relación escalar común en este estilo de arte rupestre que busca posicionar a los animales en un rol protagónico en la escena visual (Ballester 2018). 


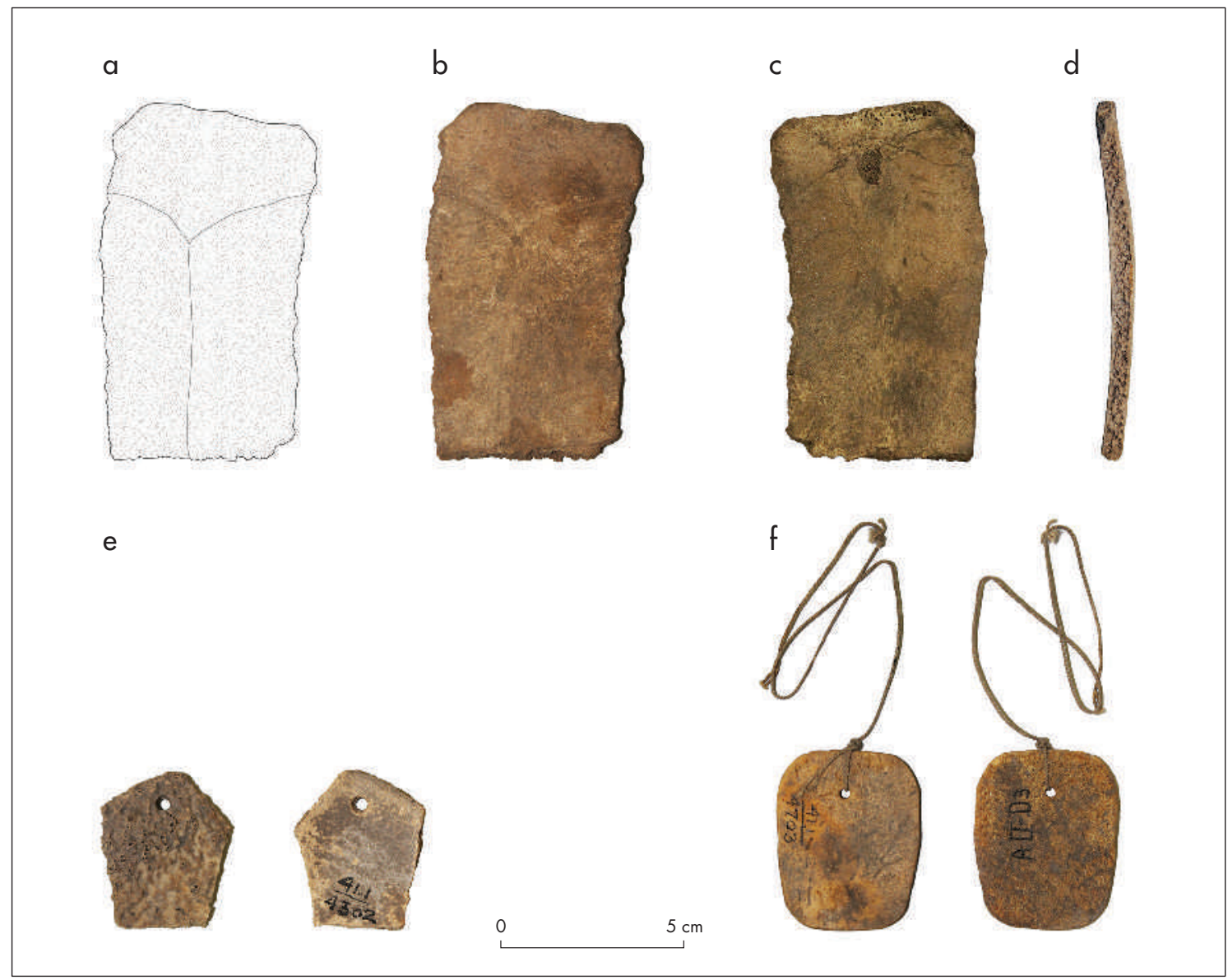

Figura 6. Restos arqueológicos de tortuga marina del sitio de PML-5: a-d) fragmento de caparazón de tortuga trabajado en forma rectangular, capa B; e) colgante de forma pentagonal con un orificio circular, capa D3; f) colgante de forma subrectangular de vértices curvos, con un orificio circular y un cordel amarrado, capa A. Figure 6. Archeological sea turtle remains from the PML-5 site: a-d) turtle shell fragment worked into a rectangular shape, Layer B; $\boldsymbol{e}$ ) pentagonal pendant with a circular hole, Layer D3; f) subrectangular pendant with curved edges, with a circular hole strung with a cord, Layer A.
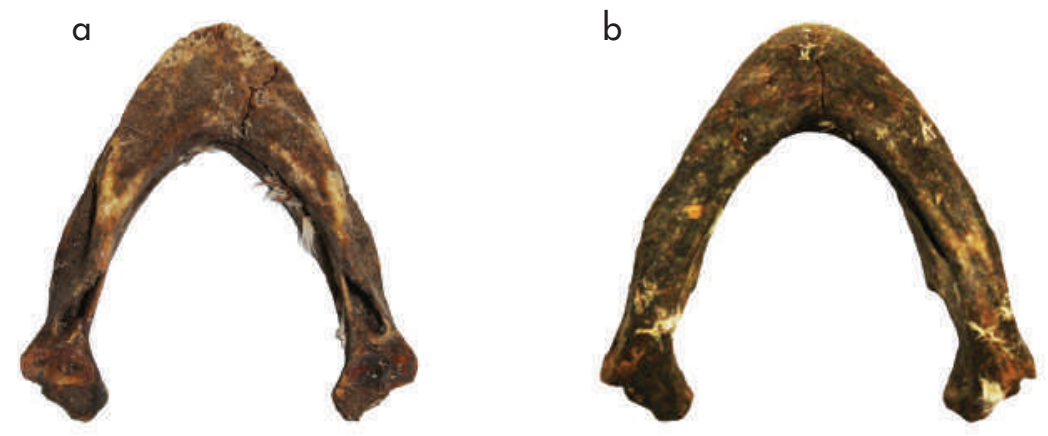

C

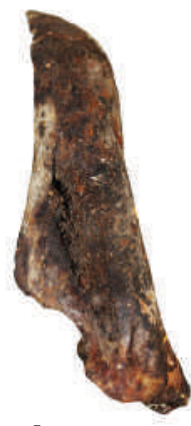

$5 \mathrm{~cm}$

Figura 7. Mandíbula arqueológica proveniente de la capa c del sitio PML-5: a) vista superior; b) vista inferior; c) vista lateral. Figure 7. Archeological mandible from Layer $C$ at the PML-5 site: $\boldsymbol{a}$ ) top view; $\boldsymbol{b}$ ) bottom view; $\boldsymbol{c}$ ) profile. 


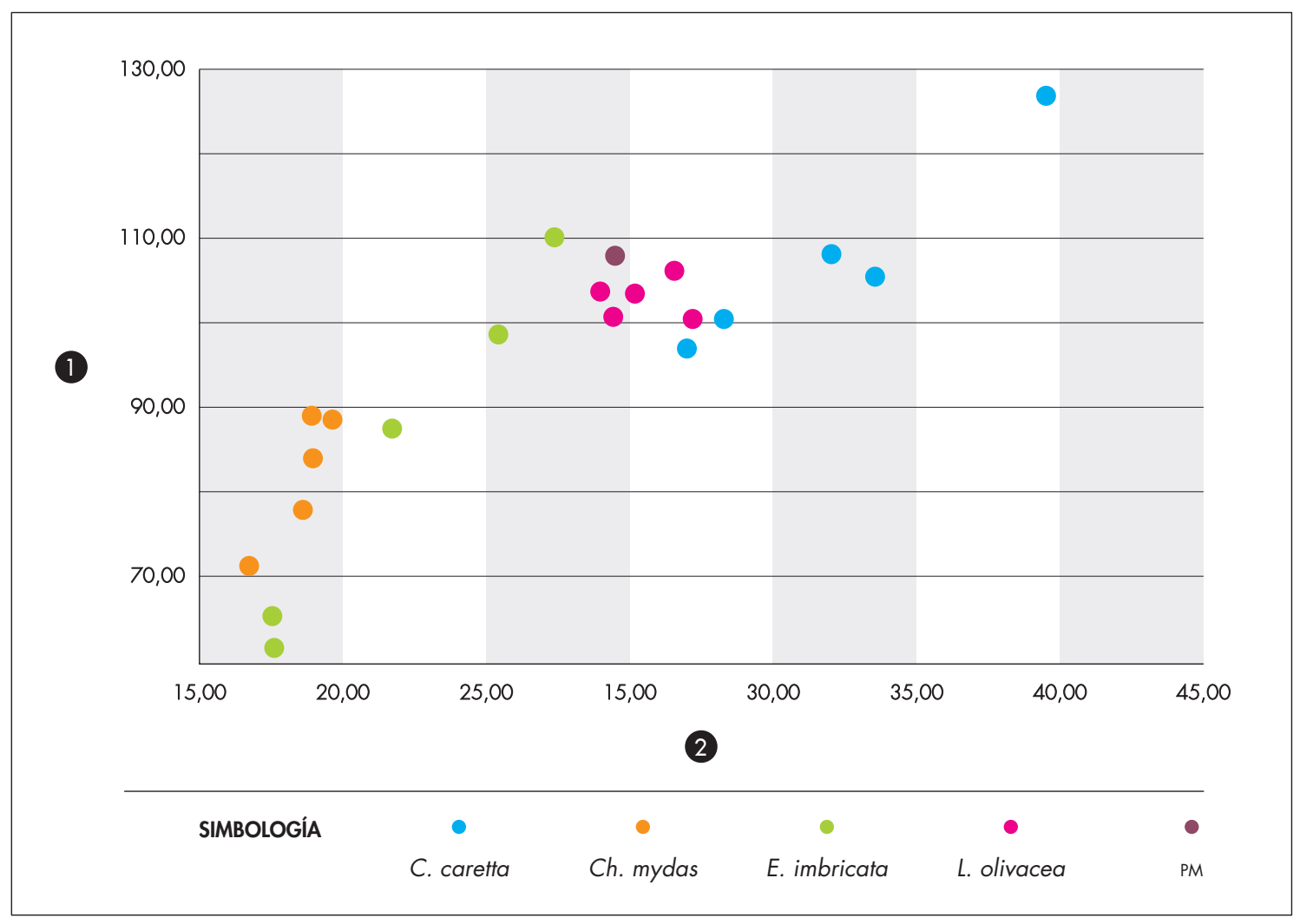

Figura 8. Relaciones métricas de mandíbulas de tortugas. Comparación entre la muestra arqueológica y las principales especies presentes en la localidad. "PM" corresponde al ejemplar de PLM-5 (ver columnas 1 y 2 en Tabla 2). Figure 8. Metric Metric ratios of turtle mandibles, comparing the archeological sample with the main species present in the locality. "PM" corresponds to the PLM-5 specimen (see columns 1 and 2 at Table 2).

En tres de los casos solo una línea de caza ancla a la presa en el sector del cuello del animal (fig. 9 a-c-d), mientras que en el motivo restante dos cuerdas desprendidas desde proa y popa de la embarcación ligan a la tortuga en una de sus aletas delanteras y la trasera de un mismo lado (fig. 9b). Este rasgo representacional es interesante, ya que mientras en el resto de las escenas de caza compuestas por otros animales marinos el cuerpo es uno de los puntos principales donde se anclan las líneas de arpón (Ballester 2018), en la tortuga no se usa este espacio central, seguramente porque en el acto de caza con arpón se privilegiaba atacar las partes blandas del animal y por razones prácticas no su caparazón.

La forma oval abultada de sus cuerpos es el principal rasgo morfológico empleado para asegurar que se trata de testudines, pero también el hecho de que sus cabezas son dibujadas como apéndices independientes, aunque adosadas al cuerpo, a diferencia de las representaciones de peces, cetáceos y otáridos. Su perspectiva de planta permite graficar diversos elementos anatómicos de forma simultánea -cabeza, cuerpo, aletas y cola-, por lo que existiría una intencionalidad por presentar los rasgos característicos de los quelonioídeos para distinguirlos del resto de los animales marinos.

Específicamente, en la escena de caza de la pintura a de la figura 9 (MD002, panel 5), se aprecia un animal con una cabeza prominente, dos extremidades delanteras largas y dos traseras cortas pegadas entre sí, sin presencia de cola. Su cuerpo muestra un caparazón que tiende a una forma circular. Estos rasgos morfológicos son similares a aquellos de L. olivacea (Boulenger 1889, Pritchard \& Mortimer 2000, Bole 2010).

El motivo b de la misma figura 9 (MD018, panel 17) presenta una escena de similares características. El animal es representado con un cuerpo elipsoidal, más largo que ancho, del cual se desprenden dos extremidades delanteras y dos traseras prominentes y prácticamente del mismo tamaño. Estas dos últimas están 
Tabla 2. Medidas de mandíbulas ( $\mathrm{mm}$ ) de chelónidos actuales y la pieza arqueológica: 1) largo máximo mandibular; 2) largo máximo de la superficie masticatoria del dentario; 3) ancho máximo mandibular; 4) alto máximo mandibular. Table 2. Mandible measurements $(\mathrm{mm})$ of present-day chelonids and the archeological piece: 1) maximum mandibular length; 2) maximum length of the dental chewing surface; 3) maximum mandibular width; 4) maximum mandibular height

\begin{tabular}{|c|c|c|c|c|c|c|}
\hline ID & TAXÓN & CÓDIGO & 1 & 2 & 3 & 4 \\
\hline 1 & Caretta caretta & 02MAR12CC01 & 108,17 & 37,04 & 103,59 & 36,49 \\
\hline 2 & Caretta caretta & 30ABR12CC01 & 126,78 & 44,52 & 116,05 & 39,69 \\
\hline 3 & Caretta caretta & 25JUN12CC02 & 105,51 & 38,56 & 105,86 & 34,74 \\
\hline 4 & Caretta caretta & 29JUN12CC02 & 100,58 & 33,28 & 91,79 & 30,69 \\
\hline 5 & Caretta caretta & 29JUN12CC06 & 97,09 & 32 & 97,65 & 31,81 \\
\hline 6 & Chelonia mydas & 20JUL12CM04 & 89,18 & 18,93 & 73,3 & 26,54 \\
\hline 7 & Chelonia mydas & 19JUL12CM05 & 71,53 & 16,74 & 59,41 & 20,1 \\
\hline 8 & Chelonia mydas & LOL23JAN13CM07 & 88,73 & 19,65 & 78,05 & 26,13 \\
\hline 9 & Chelonia mydas & 14JUL12CM01 & 78,12 & 18,61 & 66,16 & 24,36 \\
\hline 10 & Chelonia mydas & 20JUL12CM02 & 84,16 & 18,96 & 67,75 & 25,74 \\
\hline 11 & Eretmochelys imbricata & & 65,64 & 17,54 & 41,83 & 15,11 \\
\hline 12 & Eretmochelys imbricata & & 110,15 & 27,38 & 75,72 & 29,92 \\
\hline 13 & Eretmochelys imbricata & & 61,88 & 17,62 & 44,78 & 15,99 \\
\hline 14 & Eretmochelys imbricata & & 98,72 & 25,43 & 72,28 & 27,16 \\
\hline 15 & Eretmochelys imbricata & & 87,65 & 21,73 & 61,95 & 19,63 \\
\hline 16 & Lepidochelys olivacea & SILO15092102 & 103,8 & 28,98 & 95,61 & 32,28 \\
\hline 17 & Lepidochelys olivacea & MA150623LO07 & 100,79 & 29,43 & 93,48 & 31,03 \\
\hline 18 & Lepidochelys olivacea & Tortuga \# 1 & 103,51 & 30,18 & 103,65 & 34,16 \\
\hline 19 & Lepidochelys olivacea & MAC140603LO02 & 100,53 & 32,2 & 93,71 & 30,92 \\
\hline 20 & Lepidochelys olivacea & SIGLO14081402 & 106,24 & 31,56 & 96,19 & 31,46 \\
\hline 21 & Mandib. Arqueológica & & 108 & 29,5 & 102 & 30 \\
\hline
\end{tabular}


Tabla 3. Ubicación y dimensiones de los motivos de tortugas marinas en el sitio de El Médano, Taltal. Table 3. Location and dimensions of the sea turtle motifs at the El Médano site in Taltal.

\begin{tabular}{c|c|c|c|c|c}
\multicolumn{3}{|c|}{ CONTEXTO } & \multicolumn{2}{c|}{ MEDIDAS DEL MOTIVO $(\mathrm{cm})$} & FIGURA 9 \\
\cline { 1 - 4 } SITIO & SECTOR & PANEL & LARGO & ALTO & A \\
\hline El Médano & MD-002 & 5 & 6 & 5,5 & B \\
\hline El Médano & MD-018 & 17 & 17 & 14 & C \\
\hline El Médano & MD-002 & 1 & 7 & 8,5 & D \\
\hline
\end{tabular}

manifiestamente separadas una de la otra, con una cola larga entre ellas, además de una cabeza redondeada y pequeña. Los atributos reseñados son compatibles con D. coriacea (Yáñez 1951, Pritchard \& Mortimer 2000, Canales \& Álvarez 2015).

Por su parte, el quelonioídeo del motivo c (MD002, panel 1) posee un caparazón de forma semicircular, comparativamente más elipsoidal que el motivo a, alcanzando su ancho máximo en el segmento medial de este. Su cabeza es proporcionalmente grande, de extremidades poco prominentes y dimensiones similares entre las delanteras y traseras. Estas últimas no están pegadas una a la otra y entre ellas existe una pequeña cola, levemente más corta que las extremidades inferiores. Estos atributos son coincidentes con aquellos señalados para C. caretta (Boulenger 1889, Yáñez 1951, Pritchard \& Mortimer 2000, Bole 2010).

Finalmente, en el motivo d de la figura 9 (MD018, panel 16), se representó una tortuga con un cuerpo elipsoidal, una cabeza prominente y redonda, junto a dos extremidades delanteras alargadas y dos traseras de menor tamaño distantes una de otra, sin evidencia de cola. Estos rasgos la asemejan morfológicamente a Ch. mydas o C. caretta (Boulenger 1889, Yáñez 1951, Pritchard \& Mortimer 2000, Bole 2010).

\section{RELACIONES ENTRE TORTUGAS MARINAS Y SERES HUMANOS EN EL LITORAL DEL DESIERTO DE ATACAMA}

Tortugas marinas y seres humanos han establecido relaciones estrechas en la cohabitación de espacios litorales a lo largo de la historia y en diferentes partes del mundo (Ayres 1979, Frazier 2003, Allen 2007, Frazier et al. 2007, Woodrom 2010). Por lo general, las relaciones no se limitan a compartir un medio de vida, sino que es habitual que los seres humanos capturen tortugas para su alimentación (Gourou 1964, Frazier 1980, Woodrom 2003) y el aprovechamiento de huesos y caparazones como insumos en la manufactura de artefactos de diversa índole, tanto para fines prácticos, cotidianos y mundanos como para rituales simbólicos y ornamentales (Frazier 2003, 2005, Brown 2011, Frazier \& Ishihara-Brito 2012, Gillreath-Brown \& Peres 2017, 2018). Estos usos han sido documentados en sitios arqueológicos de distinta antigüedad en la península arábiga, en torno al océano Índico, en el Caribe centroamericano, el Yucatán, Norteamérica, la Polinesia y Sudamérica, demostrando su amplitud geográfica y profundidad histórica (Frazier 2005).

La caza de estos animales sirve en ciertas sociedades a sujetos específicos para posicionarse diferencialmente frente al colectivo, ya que implica poseer habilidades, destrezas y liderazgos que solo unos pocos controlan, llevando luego a la realización de ceremonias redistributivas y festines que contribuyen en el ordenamiento político de las comunidades. Así se ha documentado, por ejemplo, entre los meriam, un grupo insular del estrecho de Torres en el norte de Australia, donde la caza, distribución y consumo de tortugas marinas jugó un rol protagónico en las relaciones de generosidad y redistribución colectiva, con fines políticos y económicos (Smith \& Bliege 2000).

Complementariamente, en muchas culturas las tortugas ocupan y han ocupado valores simbólicos y papeles activos en su imaginario social, convirtiéndolas en referentes dentro del universo representacional de 


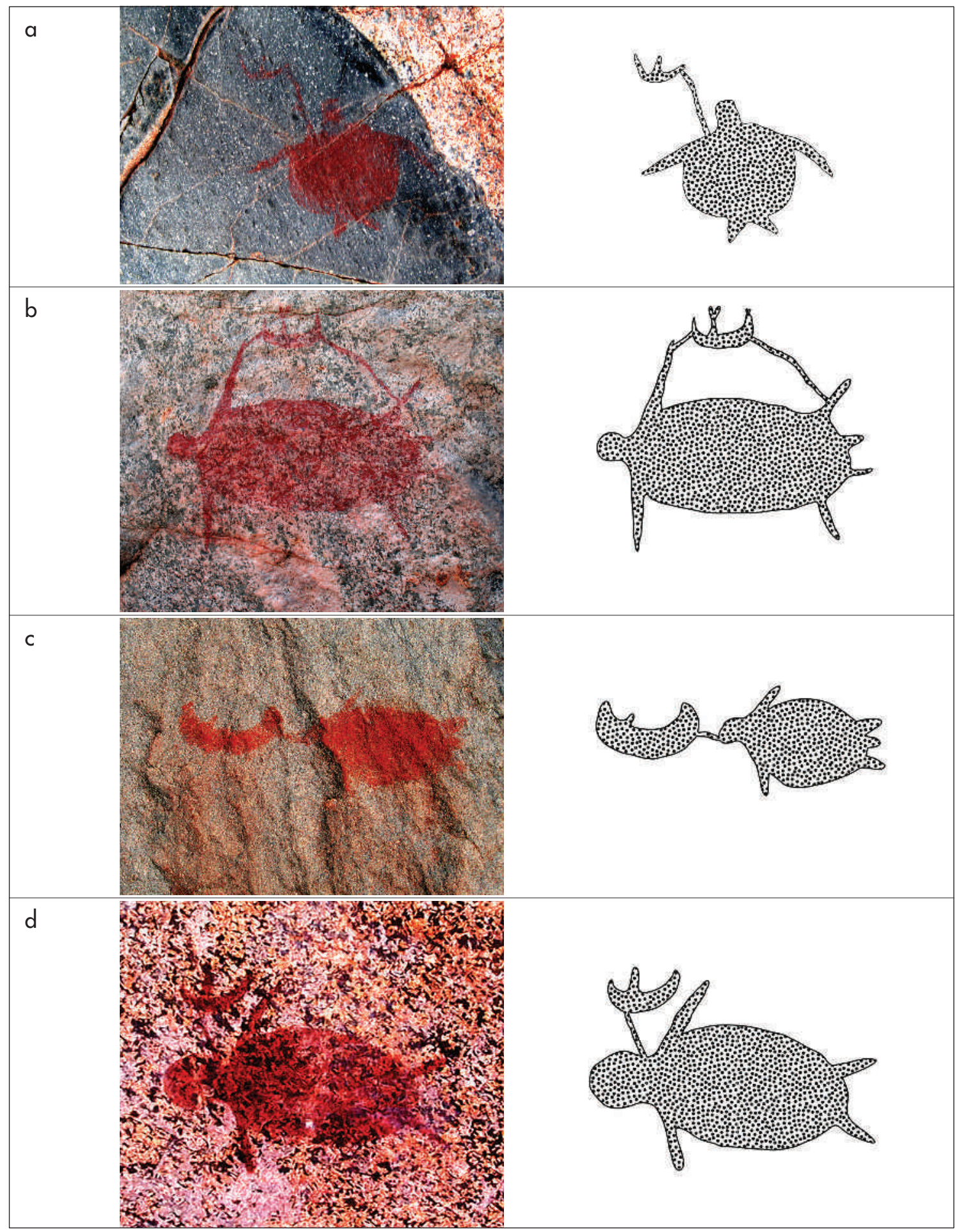

Figura 9. Motivos de tortugas marinas en escenas de caza con embarcaciones de El Médano: a) Sector MD002, panel 5; b) Sector MD018, panel 17; c) Sector MD002, panel 1; d) Sector MD018, panel 16 (fotografías: Francisco Gallardo). Figure 9. Sea turtle motifs in hunting scenes with seagoing vessels at El Médano: a) Sector MD002, Panel 5; b) Sector MD018, Panel 17; c) Sector mD002, Panel 1; d) Sector MD018, Panel 16 (Photos by: Francisco Gallardo). 
su arte rupestre, en el modelamiento de figurillas en miniatura, la confección de disfraces, además de su presencia en mitologías, cosmologías e historias orales (Frazier 2003, 2005, Nabhan 2003, Canales \& Álvarez 2015). Casos emblemáticos son, por ejemplo, las coloridas tortugas realizadas por los pintores sobre roca de la Tierra de Arnhem en Australia (Tacon 1989) o el uso de un símbolo de tortuga en las tablillas de glifos Rongorongo encontrados en Rapa Nui (Rjabchikov 2001). Destaca el papel preponderante de las tortugas en el imaginario iroqués en Norteamérica, quienes consideraban a su mundo como la isla Tortuga y poseían un clan Tortuga que predominaba frente al resto, además de utilizar una serie de artefactos manufacturados desde sus cuerpos para fines simbólicos (Pearce 2005). La noción del mundo posado en el caparazón de una tortuga es compartida también por otros nativos norteamericanos, como los antiguos residentes del área de Delaware (Miller 1974). Los seris de la costa desértica de Sonora en el golfo de California, por su parte, eran expertos cazadores de tortugas marinas con embarcaciones y arpones, y aprovechaban sus carnes para la alimentación y sus cuerpos como insumos para fabricar artefactos de distinta índole, integrándolas adicionalmente en sus mitologías y como referente para clasificar uno de sus clanes (McGhee 1898).

En Chile, las referencias arqueológicas al uso de tortugas por seres humanos en tiempos precolombinos se remiten a pocos casos (Bird 1943, Spahni 1967, Frazier \& Bonavia 2000). Además de la información proporcionada por Bird (1943) para Playa Miller y Quiani, destaca el antecedente reportado por Spahni (1967), quien excavó diversos cementerios en la desembocadura del río Loa (fig. 1). En una de las tumbas, la número 13 del Cementerio 5, más tarde llamado CaH02 y atribuido al Período Intermedio Tardío (1000-500 cal. AP) (Núñez 1971), Spahni descubrió un enterratorio colectivo que contenía tres individuos adultos junto a un ajuar compuesto por arpones, pesas de pesca, un capacho, anzuelos de cobre, un cuchillo metálico enmangado, cinco vasijas cerámicas y ovillos de lana, todo cubierto de gran cantidad de polvo rojo como parte del arreglo funerario. Cerrando la tumba y a modo de tapa de la sepultura había un caparazón de tortuga, de Ch. mydas, según el autor (Spahni 1967: 209). El hallazgo destaca por el uso simbólico y ritual del caparazón completo para sellar y contener un sepulcro con diversos elementos artefactuales alusivos al rol del cazador marino.
Nuestro estudio de las colecciones de PML-5 permitió definir un conjunto óseo reducido de quelónidos, todos provenientes de un basural doméstico. Dependiendo de la diagnosis del material, se pudo establecer distintos grados de identificación de los restos recuperados. La mandíbula corresponde a la especie L. olivacea, mientras que los tres fragmentos óseos de caparazón fueron atribuidos a Cheloniidae indet., descartando la presencia de $D$. coriacea en el conjunto. Es importante añadir que $L$. olivacea ha sido avistada en las costas de Arica inmediatas al sitio arqueológico y en el litoral de Tarapacá (Frazier \& Salas 1982, Chandler 1991, Azócar et al. 2011). Del conjunto destacan dos colgantes finamente trabajados sobre placas (fig. 6). Su desecho en un contexto doméstico demuestra su uso cotidiano y en vida por las personas, pero también su descarte. En principio, la presencia de una mandíbula y restos de caparazón permiten pensar que uno o varios de estos animales fueron llevados al sitio faenados o completos, donde pudieron ser procesados para su consumo -sea como alimento, materia prima o de otro tipo-, y sus placas utilizadas como soporte para la confección de adornos.

$\mathrm{El}$ acceso a estos recursos es discutible, ya que pudieron ser capturadas a través de embarcaciones -pues las tortugas no desovan en el norte de Chile- o bien colectados los huesos de algún animal muerto. Esta última opción fue sin duda posible, pero lamentablemente en Chile no existen estudios sistemáticos y de largo plazo sobre sus varazones que nos permitan inferir patrones y correlacionar datos (Azócar et al. 2011). En este sentido, nos inclinamos por la primera opción debido a la existencia de representaciones de caza en las pinturas rupestres de El Médano, no solo por lo explícito de las escenas, sino también porque en ellas graficaron intencionalmente elementos técnicos fundamentales para poder llevar adelante la práctica.

Evidentemente, la escasez de registros arqueológicos de tortugas no se debe a su inexistencia en tiempos precolombinos ni al desinterés de los colectivos humanos en entablar relaciones con ellas. Se trata principalmente de un sesgo provocado por los mismos investigadores al sobrerrepresentar ciertas especies animales en desmedro de otras. El foco de los análisis zooarqueológicos en el área se ha centrado fundamentalmente en aquellas especies tradicionales, abundantes y/o más sencillas de identificar, como peces, otáridos y camélidos, en desmedro de aquellas más escasas y menos habituales, aunque no por eso menos importantes y significativas en 
cuanto a su valor sociocultural, como las tortugas. Esto es particularmente cierto para los contextos arqueológicos costeros del norte de Chile, en donde los estudios faunísticos, desarrollados fundamentalmente sobre conjuntos óseos de cronología "arcaica” (ca. 11000-3000 años cal. AP), han caracterizado a los grupos litorales como esencialmente pescadores y recolectores, en gran parte debido a la abrumadora presencia de restos de peces (litorales y pelágicos) y moluscos entre sus basuras, con un aporte comparativamente menor de otáridos y aves (Bird 1943, Boisset et al. 1969, Llagostera 1979, Llagostera et al. 1999, Olguín et al. 2015, Ballester et al. 2017, entre otros). Sin embargo, recientes trabajos zooarqueológicos efectuados con mayor detalle, han ampliado el universo de taxones explotados, al incorporar peces xifoideos e istiofóridos, junto a delfínidos y otros cetáceos, en sitios de temporalidad variable que fluctúa desde momentos tempranos hasta tiempos tardíos de la prehistoria local (ca. 7000-500 cal. AP) (Mostny 1942; Bird 1943; Núñez et al. 1974; Schiappacasse \& Niemeyer 1984; Salazar et al. 2010; Contreras et al. 2011; Palma et al. 2012; Béarez et al. 2015; Olguín et al. 2014, 2015; Castro et al. 2016; Rebolledo et al. 2016, Ballester et al. 2017, entre otros).

Así mismo, los estudios faunísticos se concentran, hasta la fecha, primordialmente en las basuras domésticas, cuando su presencia en contextos funerarios a modo de objetos es también abundante. En efecto, desde que los sitios funerarios se vuelven populares en la secuencia litoral, diversos artefactos manufacturados sobre materias primas animales ofrendados en las tumbas dejan en evidencia una tendencia inversa a aquella advertida en las basuras domésticas, existiendo prácticamente una ausencia de peces versus un notorio predominio en el uso simbólico de aves, camélidos, cánidos, otáridos y cetáceos, además de algunos animales foráneos al litoral (Latcham 1938, Mostny 1964, Spahni 1967, Barraza 1981, Labarca et al. 2015, 2017, Valenzuela et al. 2015, entre otros).

Respecto de las tortugas, por ahora solo contamos con la referencia de Spahni (1967) señalada más arriba, lo que demuestra la necesidad de evaluar distintos tipos de sitios arqueológicos (funerarios y domésticos) y soportes materiales (desechos y artefactos), tanto aquellos más representados como los menos frecuentes en los contextos, con la finalidad de comprender de forma integral y holística la relación entre humanos y animales en el pasado en sus distintas esferas y prácticas.
Más al sur, en las quebradas de Taltal (fig. 1), las pinturas rupestres de El Médano permiten discutir las relaciones entre humanos y tortugas marinas desde al menos tres aristas. La primera de ellas tiene que ver con la necesidad de representar las tortugas diferenciándolas de los otros animales marinos. Existe una intención por graficarlas a través de gestos y elementos para que el espectador pueda reconocerlas y distinguirlas, tanto de las otras presas marinas no-tortugas como también entre las diversas especies de tortugas. Este último gesto de distinción fue sutil, logrado a través de la morfología de sus caparazones, proporciones de sus extremidades delanteras y traseras, así como la forma y tamaño de sus cabezas, junto a la presencia o ausencia de cola. De acuerdo con estos rasgos se sugeriría la representación de al menos tres especies de tortugas marinas en los motivos rupestres, C. caretta, L. olivacea y D. coriacea. Este juego de intenciones y distinciones debió fundarse en un acabado conocimiento de la anatomía y fisionomía de los animales marinos. Un cuerpo de saberes construido a lo largo de generaciones a través de un contacto directo con ellas, su avistamiento, observación y estudio de rasgos corporales, etológicos y relacionales. Es destacable el hecho de que el análisis pictórico reveló una diversidad mayor de taxones que los estudios zooarqueológicos, lo que refuerza la necesaria complementariedad entre distintas fuentes de información.

La segunda arista refiere a las asociaciones pictóricas en las que se encuentran las tortugas. Las cuatro representaciones del animal están insertas en escenas de caza marina, incluyendo embarcaciones, líneas de arpón y navegantes. Existe una intencionalidad en presentarlas gráficamente en estos contextos, resaltando por un lado el hecho de que eran cazadas en el mar y no solo se accedía a ellas en las playas -vivas o muertas-. Expresa, además, el método y la forma en que esta práctica se realizaba, ya que las imágenes enfatizan actos individuales: una presa, una balsa y un navegante por escena (relación 1:1:1 entre las unidades de la composición). Como dijimos, junto a los detalles realistas con los que pintaron a los animales, se preocuparon por representar los lugares de impacto de los arpones exclusivamente en las partes blandas de su cuerpo, como la cabeza, el cuello y sus aletas, excluyendo el caparazón, impenetrable a través de esta tecnología de caza.

Finalmente, el uso de las tortugas en los motivos rupestres demuestra el valor de esta especie en la cultura material visual e imaginario social de los cazadores 
recolectores marinos del desierto de Atacama. En este sentido, las tortugas adquirieron un valor que iba más allá de lo meramente subsistencial o como materia prima, abarcando el ámbito de las representaciones sociales como referentes visuales dentro de su propia construcción cultural. En el arte rupestre de El Médano, la caza marina de tortugas y del resto de las especies fue sobrerrepresentada respecto del amplio universo de prácticas sociales realizadas por estos colectivos litorales para su reproducción, como la recolección de moluscos, la pesca con anzuelos, la producción artesanal, la cocina, la construcción de sus hogares, entre otras. Tal distinción fue manejada probablemente por los mismos sujetos para posicionar la práctica de la caza y sus agentes en un lugar privilegiado frente al resto del colectivo social (Ballester 2018).

\section{CONCLUSIONES}

Aunque el conjunto de piezas es reducido y posee escaso valor cuantitativo, este estudio permitió ampliar el universo de taxones con los cuales los colectivos humanos establecieron relaciones interespecie, sumándose así a otras especies inusuales y subrepresentadas en el registro zooarqueológico. Reveló, además, que es posible y necesario realizar una arqueología crítica desde colecciones depositadas en museos, ya que los antiguos análisis e inferencias quedaron muchas veces solo a nivel de las preguntas de otra época, requiriendo de constantes revisiones. Por otro lado, el estudio ha demostrado la importancia de desarrollar más análisis faunísticos detallados y desde diversas fuentes materiales. La complementariedad de los trabajos pictóricos y zooarqueológicos ha quedado de manifiesto al permitir identificar con el primero de los soportes un número mayor de formas que con el segundo de estos. De igual manera, las escenas de caza han precisado los modos de obtención de los quelonioídeos, mientras que los trabajos osteológicos permitieron definir algunos de los posibles usos luego de su captura.

Tanto los contextos arqueológicos estudiados, como aquellos pocos que se encontraban en la bibliografía, explicitan las esferas en las que seres humanos y tortugas marinas establecieron vínculos y relaciones interespecies en el pasado prehispánico del litoral del desierto de Atacama. No solamente cohabitaron los mismos espacios físicos, tal como sucede hasta hoy, sino que también los humanos las cazaron en el mar con la ayuda de embarcaciones y arpones, tal vez para alimentarse y con seguridad para producir bienes de alto valor social sobre los insumos obtenidos de sus cuerpos, como colgantes y adornos que podían ser utilizados cotidianamente, en instancias especiales o como ofrendas funerarias a sus ancestros. Dichos animales fueron seleccionados y considerados, además, como referentes para el arte rupestre, donde se plasmaron y materializaron profundos saberes sobre su anatomía, técnicas de captura, diferencias y relaciones entre especies.

A partir de la combinación de los estudios zooarqueológicos y pictóricos es posible asegurar que dichas relaciones no se establecieron únicamente con una especie de tortugas, sino con una diversidad de ellas, al menos con la olivácea (L. olivacea), y posiblemente con la boba (C. caretta) y la laúd (D. coriacea). Si bien corresponde a una evidencia arqueológica efímera y poco abundante en comparación con la de otros animales, estos selectos casos ejemplifican el valor que tuvieron las tortugas para los colectivos humanos del litoral, quienes crearon con ellas relaciones interespecies heterogéneas, complejas y multidimensionales que iban más allá de la subsistencia, hacia distintos campos de lo social, económico, político y simbólico.

Agradecimientos Proyecto fondecyt 1160045. A Sumru Aricanli, encargada del Laboratorio Junius Bird del American Museum of Natural History de New York (AMNH-NY). A las instituciones AMNH-NY y al Museo Nacional de Historia Natural de Santiago de Chile, especialmente la sección de Zoología y a su encargado, Herman Núñez. Colaboraron también en esta investigación facilitando datos métricos de tortugas actuales, Catherine E. Hart, el Grupo Tortuguero de las Californias A. C., Víctor Cruz, Helena Huerta y el Centro Interdisciplinario de Ciencias Marinas del Instituto Politécnico Nacional (CICIMAR-IPN). A Jorge Gibbons del Instituto de la Patagonia por su ayuda en la identificación de las tortugas en el arte rupestre de El Médano, y a Francisco Gallardo por el material fotográfico y a Marcela Sepúlveda por su colaboración en la investigación. 


\section{REFERENCIAS}

Allen, M. 2007. Three millennia of human and sea turtle interactions in remote Oceania. Coral Reefs 26: 959-970. Berlín-Heidelberg.

Ayres, W., 1979. Easter Island fishing. Asian Perspective 22 (1): 61-92. Changwon.

Azócar, J., Olguín, A. \& Gálvez, P. 2011. Diagnóstico sobre las tortugas marinas de Chile. Chile: Instituto de Fomento Pesquero, División de Investigación Pesquera.

Ballester, B. 2016. El tiempo de El Médano. Taltalia 9: 49-62. Taltal.

BALlester, B. 2017. La pesca y la caza marina en el desierto de Atacama: luces conceptuales desde los documentos escritos (s. XVI-XIX). Cultura-Hombre-Sociedad 27 (2): 89-120. Temuco.

BALlester, B. 2018. El Médano rock art style: izcuña paintings and the marine hunter-gatherers of the Atacama desert. Antiquity 92 (361): 132-148. Cambridge.

Ballester, B., Calás, E., Pelegrino, C., Vidal, E. \& Aguilera, P. 2017. La vida en comunidad de los cazadores-pescadores marinos del desierto de Atacama (4000-2000 cal. AC). En Monumentos funerarios de la costa del desierto de Atacama. Los cazadores-recolectores marinos y sus intercambios (500 AC-700 DC), F. Gallardo, B. Ballester \& N. Fuenzalida, Eds., pp. 183-197. Santiago: CIIR \& SCHA.

Ballester, B. \& Gallardo, F. 2016. Painting a lost world. The red rock art of El Médano. Current World Archaeology 77: 36-38. Oxford.

Ballester, B., Gallardo, F. \& Aguilera, P. 2015. Representaciones que navegan más allá de sus aguas: una pintura estilo El Médano a más de $250 \mathrm{~km}$ de su sitio homónimo. Boletín de la Sociedad Chilena de Arqueología 45: 81-94. Santiago.

Ballester, B., Gibbons, J., Quiroz, D. \& Álvarez, J. 2018. Aletas, colas, arpones, líneas, balsas y cazadores: nuevas pinturas para nuevas miradas sobre el estilo de arte rupestre de El Médano (norte de Chile). En Actas del xx Congreso Nacional de Arqueología Chilena. Concepción: sCHA. En Prensa.

Barraza, A. 1981. Descripción, análisis y funcionalidad. Colección Capdeville Taltal-Chile. Memoria para optar al título de Arqueólogo, Universidad del Norte, Antofagasta.

Béarez, P., Fuentes-Mucherl, F., Rebolledo, S., Salazar, D. \& Olguín, L. 2015. Billfish foraging along the northern coast of Chile during the Middle Holocene (7400-5900 cal. вр). Journal of Anthropological Archaeology 41: 185-195.

Berenguer, J. 2009. Las pinturas de El Médano, norte de Chile: 25 años después de Mostny y Niemeyer. Boletín del Museo Chileno de Arte Precolombino 14 (2): 57-95. Santiago.

BIRD, J. 1943. Excavations in northern Chile. Anthropological papers of the American Museum of Natural History 38 (4): 173-318. Nueva York.

BitTmanN, B. 1986. Recursos naturales renovables de la costa del norte de Chile: modos de obtención y uso. En Etno- grafía e historia del mundo andino: continuidad y cambio, S. Masuda, Ed., pp. 269-334. Tokio: Universidad de Tokio.

Boisset, G., Llagostera, A. \& Salas, E. 1969. Excavaciones arqueológicas en caleta Abtao. Antofagasta. En Actas del v Congreso Nacional de Arqueología, pp. 75-152. La Serena: DIBAM.

BolE, C. 2010. Étude ostéo-morphométrique des tortues marines de la super-famille des Chelonioidea. Thèse pour obtenir le grade de Docteur du Muséum National d'Histoire Naturelle. París.

Boulenger, G. 1889. Catalogue of the Chelonians, Rhynchooephalians and crocodiles in the British Museum. Londres: Printed by Order of the Trustees.

BRown, A. 2011. An exploration of turtle shell rattle manufacture in the Mississippian Period. Anthropology Senior Thesis, Middle Tennessee State University, Tennessee.

Camus, P. \& Andrade, Y. 1999. Diversidad de comunidades intermareales rocosas del norte de Chile y el efecto potencial de la surgencia costera. Revista Chilena de Historia Natural 72: 389-410. Santiago.

Canales, C. \& Álvarez, R. 2015. History, science and conservation of sea turtles in Chile. En Successful conservation strategies for sea turtles: achievements and challenges, $\mathrm{M}$. Lara, J. Rodríguez \& R. Riosmena, Eds., pp. 1-23. México: Nova Editores.

Castelleti, J., 2007. Patrón de asentamiento y uso de recursos a través de la secuencia ocupacional prehispánica en la costa de Taltal. Tesis para optar al grado de Magíster en Antropología con mención en Arqueología, Universidad Católica del Norte. Antofagasta.

Castelleti, J., Goguitchaichvili, A., Solís, C., RodríGuez, M. \& Morales, J. 2015. Evidencia de tempranas manifestaciones rupestres en la costa del desierto de Atacama (25ㅇ). Arqueología Iberoamericana 28: 16-21. <http://www.laiesken.net/arqueologia/archivo/2015/28/3> (Consultado 19 septiembre 2018).

Castro, V., Aldunate, C., Varela, V., Olguín, L., Andrade, P., García-Albarido, F., Rubio, F., Castro, P., MaldoNADO, A. \& RUZ, J. 2016. Ocupaciones arcaicas y probables evidencias de navegación temprana en la costa arreica de Antofagasta, Chile. Chungara 48 (4): 503-530. Arica.

Chandler, M. 1991. New records of marine turtles in Chile. Marine Turtle Newsletter 52: 8-11. Durham.

Contreras, R. 2010. Recolección y pesca: pasado y presente en la costa de Taltal. Taltalia 3: 57-86. Taltal.

Contreras, R., NúÑEz, P. \& RodríGuez, O. 2008. El Médano: reflexiones antropológicas en torno a la cosmovisión de los habitantes prehispánicos de la costa sur del Norte Grande. Taltalia 1: 87-122. Taltal.

Contreras, R., Núñez, P., Llagostera, A., Cruz, J., San Francisco, A., Ballester, B., Rodríguez, O. \& Becerra, G. 2011. Un conglomerado del Período Arcaico Costero Medio del área Taltal Paposo, norte de Chile. Taltalia 4: 7-31. Taltal. 
Daneri, G., Dellarrossa, V., Quiñones, R., Jacob, B., Moreno, P. \& Ulloa, O. 2000. Primary production and community respiration in the Humboldt Current system off Chile and associated oceanic areas. Marine Ecology Progress Series 197: 41-49. Oldendorf/Luhe.

Donoso-Barros, R. 1965. Distribución de las tortugas en Sudamérica. Noticiario Mensual del Museo Nacional de Historia Natural 107: 1-5. Santiago.

Escobar, M. 2015. Para vivir en Cobija: prevalencia del modo de vida costero en Atacama. Chungara 47 (2): 303-318. Arica.

Frazier, J. 1980. Exploitation of marine turtles in the Indian Ocean. Human Ecology 8 (4): 329-370. Nueva York.

Frazier, J. 1990. Marine turtles in Chile: an update. En Proceedings of the Tenth Annual Workshop of Sea Turtle Biology and Conservation, T. Richardson, J. Richardson \& M. Donnelly., Eds., pp. 39-41. Miami: Department of Commerce.

Frazier, J. 2003. Prehistoric and ancient historic interactions between humans and marine turtles. En The biology of sea turtles, P. Luz, J. Musick \& J. Wyneken, Eds., Volumen 2, pp. 1-38. Boca Ratón: CRC Press.

Frazier, J. 2005. Marine turtles - the ultimate tool kit: a review of worked bones of marine turtles. En From hooves to horns, from mollusc to mammoth: manufacture and use of bone artefacts from prehistoric times to the present, $\mathrm{H}$. Luik, A. Choyke, C. Batey \& L. Lõugas, Eds., pp. 359-382. Proceedings of the 4 th Meeting of the ICAZ Worked Bone Research Group at Tallinn, 26th-31st of August 2003. Estonia: Muinasaja Teadus 15.

Frazier, J., Arauz, R., Chevalier, J., Formia, A., Fretey, J., Godfrey, M., Márquez, R., Pandav, B. \& Shanker, R. 2007. Human-Sea turtle interaction at sea. En Biology and conservation of Ridley Sea Turtles, P. Plotkin, Ed., pp. 253-295. Baltimore: The John Hopkins University Press.

Frazier, J. \& Bonavia, D. 2000. Prehispanic marine turtles in Perú: where were they? En Proceedings of the Eighteenth International Sea Turtle Symposium, A. Abreu-Grobois, R. Briceño-Dueñas, R. Márquez-Millán \& L. Sarti-Martínez, Eds., pp. 243-245. Miami: Southeast Fisheries Science Center.

Frazier, J. \& Ishihara-Brito, R. 2012. The occurrence of tortoiseshell on a pre-hispanic aya mosaic mask. Antiquity 86: 825-837. Cambridge.

Frazier, J. \& Salas, S. 1982. Tortugas marinas en Chile. Boletín del Museo Nacional de Historia Natural 39: 63-80. Santiago.

GAFFNEY, E. 1979. Comparative cranial morphology of recent and fossil turtles. Bulletin of the American Museum of Natural History 164: 65-376. Nueva York.

Gallardo, F., Cabello, G., Pimentel, G., Sepúlveda, M. \& Cornejo, L. 2012. Flujos de información visual, interacción social y pinturas rupestres en el desierto de Atacama (norte de Chile). Estudios Atacameños 43: 35-52. San Pedro de Atacama.

Gillreath-Brown, A. \& Peres, T. 2017. Identifying turtle shell rattles in the archaeological record of the southeastern United States. Ethnobiology Letters 8 (1):109-114. Tacoma.
Gillreath-Brown, A. \& Peres, T. 2018. An experimental study of turtle shell rattle production and the implications for archaeofaunal assemblages. PLOS ONE 13 (8): e0201472. $<$ https://doi.org/10.1371/journal.pone.0201472> (Consultado 13 septiembre 2018).

Goguitchaichvili, A., Morales, J., Urrutia-Fucugauchi, J., Soler, A., Acosta, G. \& Castelleti, J. 2016. The use of pictorial remanent magnetization as a dating tool: state of the art and perspectives. Journal of Archaeological Science: Reports 8: 15-21.

Gourou, P. 1964. L'homme et la tortue. L'Homme 4 (3): 110117. París.

IbARRA-VidAL, H. \& ORTIZ, J. 1990. Nuevos registros y ampliación de la distribución geográfica de algunas tortugas marinas en Chile. Boletín de la Sociedad Biológica de Concepción 61: 149-151. Concepción.

Jones, M., Werneburg, I., Curtis, N., Penrose, R., O'Higgins, P., Fagan, M. \& Evans, S. 2012. The head and neck anatomy of sea turtles (Cryptodira: Chelonioidea) and skull shape in testudines. PLOS ONE 7 (11): e47852. <https:// doi.org/10.1371/journal.pone.0047852> (Consultado 13 septiembre 2018).

Labarca, R., Calás, E. \& Prieto, A. 2017. Los artefactos óseos de contextos funerarios costeros de la rRegión de Antofagasta. En Monumentos funerarios de la costa del desierto de Atacama. Los cazadores-recolectores marinos $y$ sus intercambios (500 AC-700 DC), F. Gallardo, B. Ballester \& N. Fuenzalida, Eds., pp. 95-106. Santiago: CIIR \& SCHA.

Labarca, R., Calás, E., Gallardo, F., Ballester, B. \& Prieto, A. 2015. Chaetophractus vellerosus Gray 1865 (Xenarthra, Dasypodidae) en un cementerio de túmulos de la desembocadura del río Loa (Región de Antofagasta, Chile): evidencias de conexiones con el altiplano andino, Período Formativo Tardío (300 AC-500 DC). Estudios Atacameños 50: 47-58. San Pedro de Atacama.

LAtcham, R. 1938. Arqueología de la región atacameña. Santiago: Prensas de la Universidad de Chile.

LiNDBERG, I. 1967. Algunas notas sobre changos actuales en la costa de Antofagasta. Museo Regional Universidad del Norte, Iquique 1 (3): 5-17. Iquique.

Llagostera, A. 1979. 9700 years of maritime subsistence on the Pacific: an analysis by means of bioindicators in the north of Chile. American Antiquity 44 (2): 309-324. Cambridge.

Llagostera, A., Kong, I. \& Iratchet, P. 1999. Análisis ictioarqueológico del sitio La Chimba 13 (II Región, Chile). Chungara 29 (2): 163-179. Arica.

MÁrquez, R. 1990. Sea turtles of the world. An annotated and illustrated catalogue of the sea turtle species known to date. FAO Fisheries Synopsis No. 125, Volumen 11. Rome: Food and Agricultural Organization of the United Nations.

McGhee, W. 1898. The Seri indians. Annual Report of the Bureau of American Ethnology 17: 1-344. Smithsonian Institution. Washington. 
Medina, M., Araya, M. \& Vega, C. 2004. Alimentación y relaciones tróficas de peces costeros de la zona norte de Chile Invest. Mar. 32 (1): 33-47. Valparaíso.

Miller, J. 1974. Why the world is on the back of a turtle. Man 9 (2): 306-208. Londres.

Monroy, I., Borie, C., Troncoso, A., Power, X., Parra, S., Galarce, P. \& Pino, M. 2016. Navegantes del desierto. Un nuevo sitio con arte rupestre estilo El Médano en la depresión intermedia de Taltal. Taltalia 9: 27-47. Antofagasta.

Mostny, G. 1942. Informe preliminar sobre las excavaciones efectuadas en la costa chilena entre Pisagua y Coquimbo del 8 de octubre de 1941 al 15 de marzo de 1942. Boletín del Museo Nacional de Historia Natural 20: 97-102. Santiago.

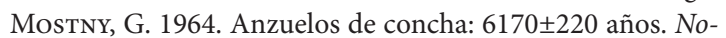
ticiario Mensual del Museo Nacional de Historia Natural 98: 7-8. Santiago.

Mostny, G. \& Niemeyer, H. 1983. Arte rupestre chileno. Santiago: Ministerio de Educación, Departamento de Extensión Cultural.

Mostny, G. \& Niemeyer, H. 1984. Arte rupestre en El Médano, II Región. Creces 9 (5): 2-5. Santiago.

Nabhan, G. 2003. Singing the turtle to sea. The comcáac (Seri) art and science of reptiles. Los Ángeles: University of California Press.

Niemeyer, H. 1985. El yacimiento de petroglifos Las Lizas (Región de Atacama, Provincia de Copiapó, Chile). En Estudios de arte rupestre, C. Aldunate, J. Berenguer \& V. Castro, Eds., pp. 131-172. Santiago: Museo Chileno de Arte Precolombino.

Niemeyer, H. 2010. Crónica de un descubrimiento. Las pinturas rupestres de El Médano, Taltal. Santiago: Museo Chileno de Arte Precolombino.

NúÑEZ, L. 1971. Secuencia y cambio en los asentamientos humanos de la desembocadura del Río Loa, en el Nnorte de Chile. Boletín de la Universidad de Chile 112: 2-25. Santiago.

NúÑEZ, P. \& Contreras. R. 2008. El arte rupestre de Taltal, norte de Chile. Taltalia 1: 77-85. Taltal.

NúÑEZ, L., Zlatar, V. \& NúÑEZ, P. 1974. Caleta Huelén 42: una aldea temprana en el norte de Chile (nota preliminar). Hombre y Cultura 2 (5): 67-103. Panamá.

Olguín, L., Castro, V., Castro, P., Peña-Villalobos, I., Ruz, J. \& Santander, B. 2015. Exploitation of faunal resources by marine hunter-gatherer groups during the Middle Holocene at the Copaca 1 site, Atacama dDesert coast. Quaternary International 373: 4-16.

Olguín, L., Salazar, D. \& Jackson, D. 2014. Tempranas evidencias de navegación y caza de especies oceánicas en la costa pacífica de Sudamérica (Taltal, 7.000 años cal. AP). Chungara 46 (2): 177-192. Arica.

Palma, C., Salazar, D. \& Salinas, H. 2012. Asentamiento y modo de vida en el Intermedio Tardío de la costa de Tocopilla, II Región, norte de Chile. En Actas del XVIII Congreso Nacional de Arqueología, pp. 175-184. Santiago: sCHA.

Palma, S. \& Apablaza, P. 2004. Abundancia estacional y distribución vertical del zooplancton gelatinoso carnívoro en un área de surgencia en el norte del Sistema de la Corriente de Humboldt. Invest. Mar. 32 (1): 49-70. Valparaíso.

Pearce, R. 2005. Turtles from Turtle Island: an archaeological perspective from Iroquoia. Ontario Archaeology 79/80: 88-108. Toronto.

PhilippI, R. 1899. Las tortugas chilenas. Anales de la Universidad de Chile 104: 727-736. Santiago.

Pritchard, P. \& Mortimer, J. 2000. Taxonomía, morfología externa e identificación de las especies. En Técnicas de investigación y manejo para la conservación de las tortugas marinas, K. Eckert, K. Bjorndal, F. Abreu-Grobois \& M. Donnelly, Eds., pp. 23-44. Washington: Grupo Especialista en Tortugas Marinas UICN/CSE.

Rebolledo, S., Béarez, P., Salazar, D. \& Fuentes, F. 2016. Maritime fishing during the Middle Holocene in the hyperarid coast of the Atacama dDesert. Quaternary International 391: 3-11.

RJABCHIKov, S. 2001. Rongorongo glyphs clarify Easter Island rock drawings. Le Journal de la Société des Océanistes 113: 215-220. París.

Salazar, D., Figueroa, V., Andrade, P., Salinas, H., Olguín, L., Power, X., Rebolledo, S., Parra, S., Orellana, H. \& URREA, J. 2015. Cronología y organización económica de las poblaciones arcaicas de la costa de Taltal. Estudios Atacameños 50: 7-46. San Pedro de Atacama.

Salazar, D., Palma, C., Salinas, H., Fuentes, F., Guendón, J. \& CAstellón, C. 2010. Reconstrucción de la secuencia ocupacional de la quebrada Mamilla, costa de Tocopilla, norte de Chile. Werkén 13: 323-346. Santiago.

Sarmiento-Devia, R., Harrod, C. \& Pacheco, A. 2015. Ecology and conservation of sea turtles in Chile. Chelonian Conservation and Biology 14 (1): 21-33. Massachusetts.

Schiappacasse, V. \& Niemeyer, H. 1984. Descripción y análisis interpretativo de un sitio arcaico temprano en la Quebrada de Camarones. Publicación Ocasional del Museo Nacional de Historia Natural 41: 1-187. Santiago.

SHeIL, C. 2013. Skeletal development of the skull of the Hawksbill Seaturtle, Eretmochelys imbricata. Journal of Morphology 274 (10): 1124-1142.

Smith, E. \& Bliege, R. 2000. Turtle hunting and tombstone opening: public generosity as costly signaling. Evolution and Human Behavior 21: 245-261.

SPAHNI, J. 1967. Recherches archéologiques à l'embouchure du rio Loa (côte du Pacifique-Chili). Journal de la Société des Américanistes 56 (1): 181-239. París.

TACON, P. 1989. Art and essence of being: symbolic and economic aspects of fish among the peoples of western Arnhem Land, Australia. En Animals into art, H. Morphy, Ed., pp. 236-250. Londres: Unwin Hyman.

Thiel, M., Macaya, E., Acuña, E., Arntz, W., Bastí́as, H., Brokordt, K., Camus, P., Castilla, J., Castro, L., Cortés, M., Dumont, C., Escribano, R., Fernández, M., Gajardo, J., Gaymer, C., Gómez, I., González, A., 
González, H., Haye, P., Illanes, J., Iriarte, J., LanceLlotti, D., Luna-Jorquera, G., Luxoro, C., ManríqueZ, P., Marín, V., Muñoz, P., Navarrete, S., Pérez, E., Poulin, E., Sellanes, J., Sepúlveda, H., Stotz, W., Tala, F., Thomas, A., Vargas, C., VÁsquez, J. \& Vega, J. 2007. The Humboldt Current system of northern and central Chile: oceanographic processes, ecological interactions and socioeconomic feedback. Oceanogr. Mar. Biol. Ann. Rev. 45: 195-344.

Valenzuela, D., C. Santoro, C., J. Capriles, J., M. Quinteros, M., R. Peredo, R., E. Gayo, E., I. Montt I. \& M. SepúlvedA, M. 2015. Consumption of animals beyond diet in the Atacama desert, northern Chile (13.000-410 BP): Comparing rock art motifs and archaeofaunal records. Journal of Anthropological Archaeology 40: 250-265.

Woodrom, R. 2003. Écologie des tortues marines et archéologie: une étude de cas destinée à comprendre l'importance des données archéologiques dans les sciences de la mer. Ressources marines et traditions-Bulletin de la ICPs 15: 26-31.

Woodrom, R. 2010. Forbidden sea turtles: traditional laws pertaining to sea turtle consumption in Polynesia (including the Polynesian outliers). Conservation and Society 8 (1): 89-97.

WynEken, J. 2001. The anatomy of sea turtles. U. s. Department of Commerce NOAA Technical Memorandum NMFS-SEFSC-470.

WyNEKEN, J. 2003. The external morphology, musculoskeletal system, and neuro-anatomy of sea turtles. En The biology of sea turtles, volume 2. CRC Marine Biology Series, P. Lutz, J. Muzick \& J. Wyneken, Eds., pp. 39-77. Boca Ratón: CRC Press.

YÁÑEZ, P. 1951. Vertebrados marinos chilenos. III Reptiles. Revista de Biología Marina 3 (1/2): 1-18. Santiago.

ZANGerL, R. 1969. The turtle shell. En Biology of the Reptilia, C. Gans, A. d'A. Bellairs \& T. Parsons, Eds., Volumen 1, pp. 311-339. Londres-Nueva York: Academic Press. 